Alma Mater Studiorum - Università di Bologna DEPARTMENT OF ECONOMICS

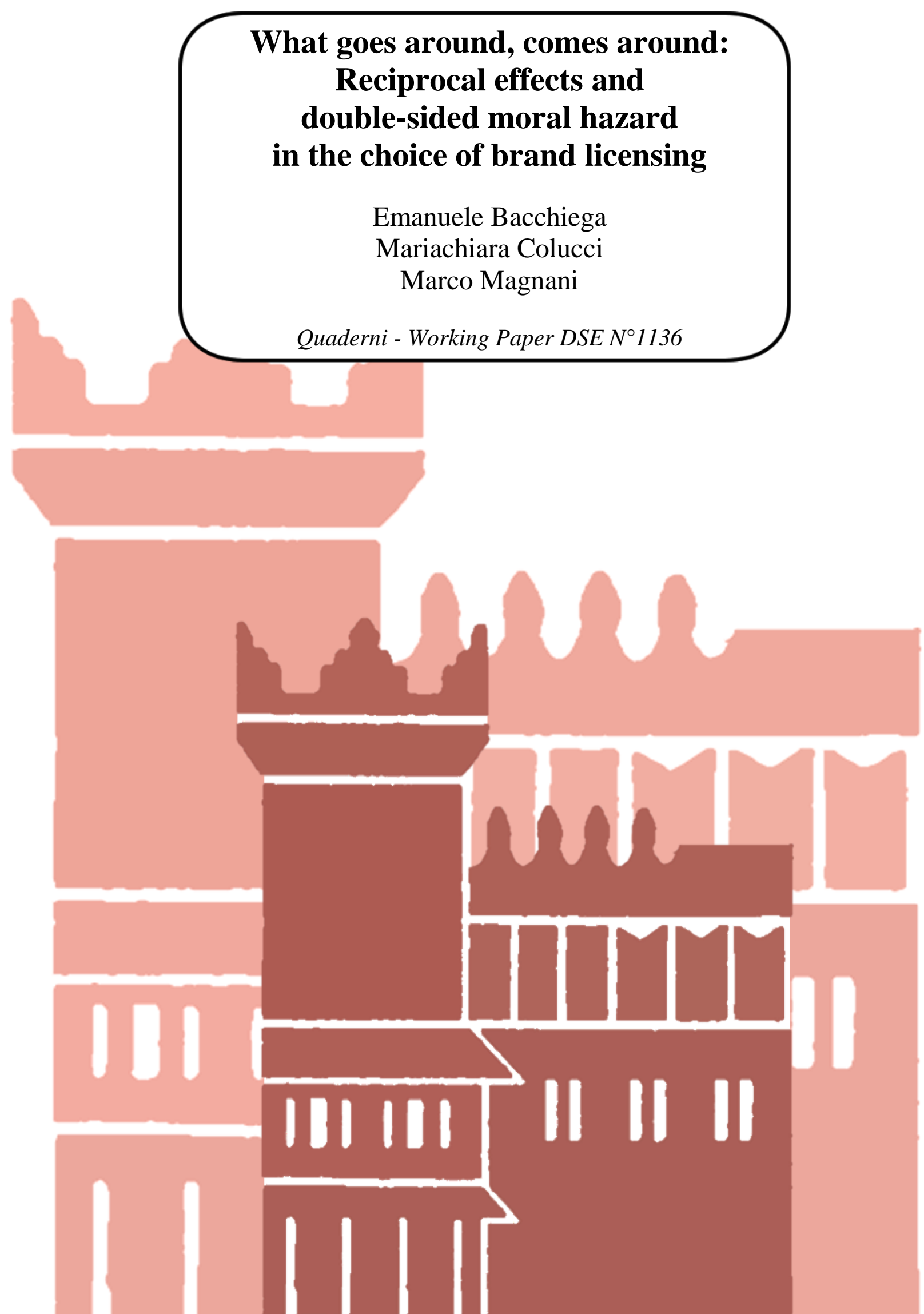




\title{
What goes around, comes around: Reciprocal effects and double-sided moral hazard in the choice of brand licensing *
}

\author{
Emanuele Bacchiega $^{\dagger a}$, Mariachiara Colucci ${ }^{\ddagger \mathrm{b}}$, and Marco Magnanis ${ }^{\S c}$ \\ ${ }^{a}$ Dipartimento di Scienze Economiche, Alma Mater Studiorum - Università di Bologna, Italy. \\ ${ }^{\mathrm{b}}$ Dipartimento di Scienze Aziendali, Alma Mater Studiorum - Università di Bologna, Italy. \\ 'Dipartimento di Scienze Economiche e Aziendali "Marco Fanno", Università di Padova, Italy.
}

October 11, 2019

\begin{abstract}
Extending a brand beyond its original product category is a major strategy for long-term profitability. A brand owner can internalize the development of the extension product, or license the brand to an external partner in order to exploit the licensee's better capabilities and higher efficiency on the targeted market. Brand extension is characterized by the presence of the socalled reciprocal effect, whereby the effort exerted to develop and market the extension has a feedback effect - either positive or negative - on the value of the parent brand. Under licensing, this effect is an externality from the standpoint of the brand owner. The licensing relationship is characterized by double-sided moral hazard, requiring an incentivizing contract; the reciprocal effect adds a further element that should be governed by the contract. Indeed, a positive effect can boost the attractiveness of licensing relative to internal development, whereas a negative one can have the opposite effect. Drawing from extant literature, we build a game-theoretical model and show how reciprocal effect, (dis)similarity between the extension product and the parent brand, and (in)efficiency of the brand owner relative to the licensee in developing the extension shape the optimal licensing contract and affect the choice between internal development and licensing.
\end{abstract}

Keywords: Brand Extension, Brand Licensing, Moral Hazard, Reciprocal Effect.

JEL classification: L12, L24

${ }^{*}$ The authors wish to thank, V. Denicolò, S. Shekar, K. Stahl, P. Zanchettin, the audiences at EEA-ESEM 2018 Cologne, JEI 2018 Barcelona, EARIE 2019 Barcelona. The usual disclaimer applies. Emanuele Bacchiega acknowledges financial support under PRIN 20157NH5TP 004.

${ }^{\dagger}$ Corresponding author, $\otimes$ emanuele.bacchiega@unibo.it

${ }^{\ddagger}$ mariachiara.colucci@unibo.it

$\S_{\square}$ marco.magnani18@unibo.it 


\section{Non-technical summary}

Extending a brand beyond its original product category is a major strategy for longterm profitability: By leveraging on the brand name, the brand owner can launch new products, enter new markets, and capture new opportunities. Brand extension enables lower product introduction costs, reduces the perceived risks for consumers, and helps to solidify the presence in market of the new product. Accordingly, recent decades have seen the launch of myriad brand extensions in an effort to drive growth; indeed, approximately $90 \%$ of new products are extensions of existing brand names. A brand owner develop internally the extension product at the cost of acquiring the necessary know-how, or license the brand to an external partner in order to exploit the licensee's better capabilities and higher efficiency on the targeted market, at the cost of -partially- forfeiting control over the extension process. Brand extension is characterized by the presence of the so-called reciprocal effect, whereby the effort exerted to develop and market the extension has a feedback effect - either positive or negative - on the value of the parent brand. The more "similar" is the extension product to the "characterizing image" of the parent brand, the stronger is the reciprocal effect. Under licensing, because of the outsourcing of the extension process, the reciprocal effect is an externality from the standpoint of the brand owner. In addition, the licensing relationship is characterized by double-sided moral hazard, because neither party can directly control the partner's effort in developing and promoting the brand and/or the extension product. The licensing contract, therefore, has to be designed both to give the parties the right incentives to nurture the brand and develop the extension, and to account for the reciprocal effect. Indeed, a positive effect can boost the attractiveness of licensing relative to internal development, whereas a negative one can have the opposite effect. Drawing from extant literature, we build a game-theoretical model and show how the size and sign of the reciprocal effect, the (dis)similarity between the extension product and the parent brand, and the (in)efficiency of the brand owner relative to the licensee in developing the extension shape the optimal licensing contract and affect the choice between internal development and licensing. 


\section{Introduction}

Extending a brand beyond its original product category represents a major strategy for companies seeking long-term profitability. In fact, by leveraging the brand equity associated with their brand names, companies can launch new products, enter new markets, and capture new opportunities. Brand extension enables lower product introduction costs, reduces the perceived risks for consumers, and helps to solidify the new product's market presence. Accordingly, recent decades have seen the launch of myriad brand extensions in an effort to drive growth. Indeed, approximately $90 \%$ of new products are extensions of existing brand names (Hariharan et al., 2014, Keller et al., 2008). Yet, this strategy can have a two-way effect: The parent brand might empower the new extension product via a direct effect, but the extension product might also enhance or diminish the equity of the parent brand. ${ }^{1}$ The management literature refers to the former case as positive reciprocal effect or brand enhancement, and to the latter as negative reciprocal effect or brand dilution (e.g., Gürhan-Canli and Maheswaran, 1998, Keller and Aaker, 1992).

For brand owners, extending their branded product portfolio requires the ownership of resources and competences that the company may not have or that may be too expensive to acquire or develop internally. In such cases, firms can manage the extension in two ways: First, they can invest resources to internally acquire or develop the extension, which implies an increase in the company's level of vertical integration. The second is to identify and select a venture partner and perform the extension through brand licensing (Colucci et al., 2008). ${ }^{2}$ Brand licensing entails the renting or leasing of the company's brand name to an external actor (e.g., LIMA, 2018, Robinson et al., 2015). This approach has proliferated over the last 30 years, allowing firms to introduce a brand to new product categories without making major investments in manufacturing or distribution activities. Under a licensing agreement, a company (the licensor) gives an industrial or retail partner (the licensee) the rights to use its brand name in return for a negotiated payment (a fee or royalties, typically a percentage of wholesale revenues). This agreement thus creates an agency relationship where both parties have different goals: The former aims to increase brand awareness, while the latter strives for commercial diffusion in order to increase its own profits (Raugust, 2012). Granted, like with all licensing agreements (such as technological licensing), there

\footnotetext{
${ }^{1}$ The parent brand is an existing brand used to create a new product called the brand extension (Aaker and Keller, 1990, John et al., 1998).

2 "[...] Porsche sunglasses, Coca-Cola clothes, and many other licensing ventures brought a new emphasis on managing brands. As an example, Ocean Pacific (OP) Sunwear, which started as clothing manufacturer, 'quit making its own products in 1980. The company felt it would function more efficiently and grow more quickly by concentrating solely on selling its name' (Day, 1985, p.1)." (Tauber, 1988, p. 26).
} 
is a risk of either party behaving opportunistically, especially in conditions of imperfect monitoring (Choi, 2001, Jayachandran et al., 2013, Robinson et al., 2015), and thereby failing to maximize the value of the relationship. On one hand, the licensor may deny support to the partner's business depending on, for example, the contract's compensation structure (i.e., royalties, a percentage of the licensee's sales and/or a lump sum, a fixed negotiated amount), the strategic relevance of the new product for the parent brand, or the possibility of replacing the licensee. Such behavior(s) may damage the licensee's profits and thereby diminish its investments in the product. On the other hand, the licensee might exert a weak effort toward the extension or fail to comply with the brand image guidelines, whether in terms of design, quality of materials used, or the use of inappropriate channels. This would ultimately undermine the proper development of the extension product. Furthermore, the behavior of the licensee may have specific effects in the framework of brand licensing: For instance, transcending the boundaries of the licensed product's market may impact the licensor's brand equity - and ultimately profits - in the other markets where it operates. In other words, a reciprocal effect (positive or negative) may occur when the extension is managed via licensing. Consequently, the success of brand licensing depends on the extent to which the licensing contract aligns the goals of both parties (as in technological licensing or franchising), as well as monitors and governs the reciprocal effect (which is specific to brand licensing).

Based on the above, this paper assumes two main objectives. First, we analyze the characteristics of the optimal brand licensing contract by evaluating how the extension product's reciprocal effect (positive or negative) influences the parent brand value. Second, we assess the conditions under which a brand owner should prefer a licensing agreement to in-house development, hereafter referred to as the choice of make-or-license.

To delve into these issues, we draw from both the management and industrial organization literatures in order to develop a strategic dynamic model where both the brand owner and the (potential) licensee can carry out the extension project. The model is characterized by the following features: First, any investment in creating and maintaining brand value is beneficial to the extension product; similarly, any investment in the extension product has a feedback effect (either positive or negative) on the brand value. Second, under licensing, both the brand owner/licensor and the licensee face a moral hazard problem as they cannot observe each other's efforts in, respectively, maintaining the brand's relevance and offering a suitable extension product. Finally, under inhouse development, the brand owner is assumed to be less cost-efficient than the potential licensee in terms of executing the extension project.

The reciprocal, or feedback, effect is the distinguishing feature of our model, differentiating our analysis from extant research on technological licensing and franchising. In particular, we assume that licensing can entail either positive (brand enhancement) or negative (brand dilution) feedback on the brand value, while the feedback from in-house production is solely positive. We assume that the actual impact of the feedback effect is mediated by the dissimilarity between the extension product and the parent brand (i.e., how they "unfit" together): the larger the dissimilarity, the lesser the feedback, all else being equal. Research has tested this effect in the context of brand 
extension (e.g., Keller and Aaker, 1992), but our study extends this suggestion to the context of business models used to carry out extensions (i.e., make-or-license). The second feature, the double-sided moral hazard, has already been investigated in the context of technological licensing (e.g., Choi, 2001), but is fairly new to the literature on brand licensing (Jayachandran et al., 2013). The core idea here is that such agreements involve non-appropriable investments that arise from a misalignment of incentives between the licensor and the licensee. Finally, in order to highlight an interesting trade-off, we disregard the case whereby the licensee is less cost-efficient than the licensor in executing the extension, which accords with the prevailing literature on technological licensing.

We characterize (i) the optimal licensing contract based on a non-linear, two-part tariff (i.e., a royalty rate and a fixed payment, following Choi (2001) and Raugust (2012)), and (ii) the brand owner's optimal choice in terms of either becoming a licensor or pursuing in-house production. We focus our analysis on the magnitude and sign of the reciprocal effect, on the perceived dissimilarity between the extension product and the parent brand (Yeung and Wyer Jr, 2005), and on the relative cost inefficiency of the brand-owner vis-à-vis the licensee in carrying out the extension project.

We find that an optimal licensing agreement exists for both in the cases of brand enhancement and brand dilution: When there is brand enhancement (dilution), a larger dissimilarity between the extension product and the parent brand causes an increase (decrease) in the optimal royalty rate. Furthermore, we show that the optimal royalty rate is larger (smaller) as the brand dilution (enhancement) increases. This result suggests that the royalty rate not only informs the incentive structure and extraction of (a part of) the licensee's profit, as typically explored in the literature, but also acts as a contractual tool for indirectly governing the feedback effect from the licensee's activity on the value of the parent brand.

As for the trade-off between licensing or in-house development, we argue that the choice crucially depends on the dissimilarity and cost-inefficiency parameter conditions. Expectedly, a large and negative reciprocal effect - combined with a low development cost for the brand owner - makes inhouse development the dominant choice; in contrast, a large and positive reciprocal effect - combined with a high development cost for the brand owner - makes licensing the better option. It is worth emphasizing that dissimilarity plays a crucial role in all the other parameter conditions. We show that for a positive reciprocal effect, a "relatively efficient" brand owner licenses the extension when the dissimilarity is low (to benefit from a large brand enhancement), but opts for in-house development when the dissimilarity increases (to avoid entering an incentivizing licensing contract). The opposite occurs when the brand owner is inefficient and the feedback effect is negative or slightly positive. Finally, we show that dissimilarity can have a non-linear effect on the choice of the optimal business model, so that in-house development is preferable for "small" and "large" dissimilarity levels, but licensing is superior for "intermediate" ones.

The remainder of this paper is organized as follows: Section 2 reviews the relevant managerial and economic literature. Section 3 develops a model of brand extension and analyzes the brand owner's optimal choice between brand licensing and in-house development. Section 4 discusses the 
results and their theoretical and empirical implications.

\section{Related literature}

Brand extension has been a central topic in the managerial literature since the 1990s (Aaker and Keller, 1990, Broniarczyk and Alba, 1994) and remains a lively area of study (e.g., de Groote et al., 2019, Hariharan et al., 2014, Miniard et al., 2018, Monga and John, 2010, Pina et al., 2013). This literature has largely examined the advantages and disadvantages associated with brand extension: The former include reducing the risks and costs of introductory marketing programs, as well as consumers' increased acceptance of the new product. The latter involve potential damage to the brand's existing products and the brand itself if the extension fails, which creates considerable risk for brand equity dilution (Aaker and Keller, 1990, Keller and Sood, 2003, Loken and John, 1993). Recent contributions have not only developed a comprehensive framework for the determinants of brand extension success, but also highlighted the antecedents and consequences of consumer attitude toward a brand extension (Czellar, 2003, Völckner and Sattler, 2006), as well as uncovered the feedback effect of extensions on the parent brand (Michel and Donthu, 2014, Pina et al., 2013, Salinas and Pérez, 2009).

The industrial organization literature, starting from the seminal work of Wernerfelt (1988) has investigated how brand extensions - using the label "umbrella branding" — work to signal quality to consumers. Because consumers cannot perfectly observe product quality, they base their expectations on the quality of the original branded product(s). Because of this quality signal, firms must carefully design business strategies to take into account the benefits and costs of exploiting such an opportunity (e.g., Cabral, 2000, Cabral, 2009, Hakenes and Peitz, 2008, Miklós-Thal, 2012, Rasmusen, 2016 and the references therein).

These strands of literature have focused on the brand extension decision per se (i.e., branded products vs. new brands) or on consumers' evaluations of brand extensions. What remains nearly untouched is the examination of how companies carry out such extensions, with the implicit assumption being that in-house development is the preferable choice (see Colucci et al., 2008 for an exception). Consequently, the extant literature has not considered the value in alternative business models for executing brand extensions, nor their possible contractual characteristics. Nonetheless, brand licensing is a widely used business tool that allows companies to extend a brand into new categories and increase its exposure in consumers' lives. Having achieved maturation and global stature, licensing now encompasses myriad industries, including entertainment, fashion, sports, publishing, music and art; in terms of revenue, the worldwide retail sales of licensed products reached an estimated US $\$ 271.6$ billion in 2017 (Loveday, 2018). The top licensing property type is entertainment/character, with The Walt Disney Company being the world's largest licensor, while fashion/apparel leads all product categories (LIMA, 2018). In particular, there has been a continuous increase in the use of corporate brand licensing especially for fashion labels in categories such as apparel, beauty, accessories and eyewear (Raugust, 2012). 
While brand licensing has helped many established brands grow rapidly, promote a lifestyle on the market, and offer a wide product range (e.g., Walt Disney, Hasbro, Christian Dior, or Armani), it has also contributed to the failure and/or dilution of important brands. ${ }^{3}$ Pierre Cardin was once the epitome of brand extension via licensing, managing 500 licensing agreements, including one for toilet-seat covers; another example is Yves Saint Laurent, which managed 60 contracts in 2001 and then cut back to 15 the next year (Corbellini and Saviolo, 2014). Beyond the issue of product over-saturation, brand dilution is typically caused when the licensor-for whom maintaining brand image and value is paramount - loses control of the brand (Raugust, 2012). One illustrative example comes from Calvin Klein: In 2000, the firm charged Warnaco Group, its licensee, with brand equity dilution for breaching the jeanswear licensing and distribution contract-namely, by distributing products through warehouse clubs that the brand owner considered unacceptable channels. The same year, Warnaco filed countersuit, accusing Calvin Klein of ineffective brand advertising and thus damaging its business (Fournier and Boer, 2002). Given situations like these, companies have decided to limit licensing-related growth by taking back control (i.e., in-house development) over some of their related businesses, with the aim of controlling the production cycle and the flow of profits.

Today, licensing is especially important for "peripheral" businesses where production and distribution specificities hold, such as, for instance in the case of fashion companies, eyewear, watches, fragrances and cosmetics, and accessories (Corbellini and Saviolo, 2014, Colucci et al., 2008). ${ }^{4}$ In licensing agreements, the licensor contributes its reputation, brand image and creativity, while the licensee offers its manufacturing and distribution know-how. Given this split, the licensor and licensee naturally have different goals and strategies. The licensor aims to nurture and strategically orient the brand, searching for an exclusive image and product positioning that increases brand awareness. The licensee's goal is to exploit consumers' brand awareness and push commercial diffusion in order to increase revenues (Raugust, 2012). In this vein, the success of a brand licensing program depends on the extent to which such an arrangement meets the goals of both parties involved. The licensor may want to receive (possibly high) royalties while controlling the partner's use of the brand, whereas the licensee may want to maximize its investments in the extension product and boost sales.

Despite its practical importance, brand licensing has received very little attention-both theoretical and empirical - from managerial research. For instance, scholars have shown how moral hazard affects royalty rates (Jayachandran et al., 2013), the financial impact of brand licensing as related to the brand "fit" (Robinson et al., 2015), and the conditions under which brand licens-

\footnotetext{
${ }^{3}$ The Walt Disney Company, Hasbro and Warner Bros. Consumer Products are among the top global licensors (Global, 2016). In the fashion industry, the use of brand licensing is broad and established, dating back to 1950s when Christian Dior, Chanel and Pierre Cardin started licensing their names (Saviolo and Giannelli, 2001).

${ }^{4}$ A notable exception is French luxury conglomerate Kering. In 2014, the firm terminated its 20-year licensing partnership with Italian eyewear producer Safilo Group for the production of Gucci-branded eyewear, so as to develop this product category in-house. In this way, Kering took control over the entire eyewear value chain (Fernie and Perry, 2019). Meanwhile, competing companies such as Tom Ford or Armani continue to rely on industrial partners to whom they license their brands.
} 
ing is preferable to internal development (Colucci et al., 2008). These works have been partially informed by research on brand extensions (e.g., Loken et al., 2010, Völckner and Sattler, 2006), which overlaps considerably with brand licensing contexts; however, there are also critical differences (Robinson et al., 2015). Both brand licensing and brand extension involve leveraging an established brand to produce and sell a new product, but licensing also entails leasing the brand to a contracted business entity (i.e., via an inter-organizational arrangement). This means that the brand owner sacrifices some control over the brand and risks becoming exposed to opportunistic behavior and brand dilution.

Industrial Organization research, on another hand has thoroughly analyzed the economics of technological licensing, particularly in the presence of innovative investments and moral hazard (see e.g. Bhattacharyya and Lafontaine, 1995, Choi, 2001, Hernández-Murillo and Llobet, 2006, Tauman and Zhao, 2018 and the references therein). The problem with the above contributions is their exclusive focus on technological licensing and franchising, which lack the reciprocal effect native to brand licensing. ${ }^{5}$

To the best of our knowledge, no attempt has been made, so far, to incorporate in a single model the analysis of the decision whether to extend a brand internally or through brand licensing, and the characterization of the optimal licensing contract, as we do in the present essay. Bridging the management and industrial organization literatures on brand extension and brand licensing, this study proposes a strategic dynamic model that can analyze the drivers behind pursuing or avoiding brand licensing. In particular, we focus on two factors that have surfaced in prior research on brand licensing, but remain under-searched.

The first is the presence of a feedback effect which is influenced by how well the extension product "fits" the parent brand, that refers to the degree of similarity (or its opposite, dissimilarity) between the parent brand and the extension. Similarity (or fit) has a dual relevance: It is one of the main drivers of brand extension success because it determines how strongly consumers transfer brand perceptions from the parent brand in its original application (i.e., the core product) to the brand in its new application (the extension product) based on the perceived fit between the two (e.g., Aaker and Keller, 1990, Bottomley and Holden, 2001, Broniarczyk and Alba, 1994, Miniard et al., 2018, Moorthy, 2012, Park et al., 1991, Völckner and Sattler, 2006). More subtly, fit influences the feedback effects of brand extensions on the parent brand. As previously discussed, brand extensions can produce reciprocal effects that enhance or diminish the equity of the parent brand: A positively evaluated extension can both strengthen the parent brand and influence the sales of established products, leading to an enhancement in brand equity. However, a failed extension can foster negative evaluations that damage not only the extension's market potential, but also the parent brand's established products, thereby leading to a dilution of brand equity (e.g., John et al.,

\footnotetext{
${ }^{5}$ Buratto and Zaccour (2009) focus on advertising strategies in a fashion licensing contract using a differential game. Here, though, licensing is seen as a win-win strategy and no brand dilution can occur, as advertising only generates positive externalities. Furthermore, the linear, ad valorem fee governing the contract is exogenous. Pnevmatikos et al. (2018) assumed that a retailer's investment in brand advertising can improve channel coordination with the upstream producer.
} 
1998, Loken and John, 1993, Swaminathan et al., 2001). Indeed, previous research suggests that similarity plays a moderating role in such reciprocal effects (e.g., Ahluwalia and Gürhan-Canli, 2000, Boush and Loken, 1991, Czellar, 2003, Gürhan-Canli and Maheswaran, 1998, Keller and Aaker, 1992, Morrin, 1999). Granted, there have been mixed results for positive and negative reciprocal effects: It seems that both brand dilution (i.e., negative reciprocal effects) and enhancement (i.e., positive reciprocal effects) occur when the similarity - between the parent brand and the extension product - is high (e.g., Gürhan-Canli and Maheswaran, 1998, Keller and Aaker, 1992, Keller and Sood, 2003, Pina et al., 2013, Swaminathan et al., 2001). In particular, increased similarity generally leads to increased knowledge and affect transfer from the extension to the parent brand; as such, consumers would likely view the extension's success or failure as possibly reflecting on the parent brand's value. Likewise, consumers may feel that a dissimilar extension's performance bears little relation to the parent brand's performance. In short, a dissimilar extension product provides little benefit and causes little damage to brand value (Pina et al., 2013). Finally, recent research has also advanced that the degree of similarity influences the organizational means deployed to create and launch the new product in the market. This is the choice of make-versus-license: Managers tend to internally develop the product categories that they perceive as similar to the parent category, even when their level of control over the licensee is high, due to the higher potential for brand damage (Colucci et al., 2008). Building on these contributions, this paper maintains that (dis)similarity moderates the feedback effects and therefore acts as a driver in the make-versus-license choice.

The second factor is the presence of double-sided moral hazard in the licensing relationship. Neither the brand owner nor the licensee can perfectly monitor the activity of the partner, which generates the risk of opportunistic behavior (Jayachandran et al., 2013). If licensees behave opportunistically, they may manufacture a poor-quality product or use inappropriate distribution channels, which would serve to devalue the brand. At the same time, the case of Calvin Klein vs. Warnaco (Fournier and Boer, 2002) neatly illustrates that the licensor can also neglect the licensee's business (through, e.g., ineffective brand advertising) and thereby cause a decrease in the licensee's sales. In this regard, a number of scholars - such as Bhattacharyya and Lafontaine (1995), Choi (2001) and Cachon and Lariviere (2005) - have addressed the presence of double-sided opportunistic behavior, though in the domain of technological licensing or franchising. For instance, Bhattacharyya and Lafontaine (1995) demonstrated that linear payments based on profit sharing can be optimal in share contracts such as franchising and sharecropping. Choi (2001) looked at the characteristics of the optimal licensing contract and related the size of the optimal royalty rate to environmental parameters. Meanwhile, Cachon and Lariviere (2005) explored the pros and cons of revenue-sharing contracts, focusing on their ability to coordinate the supply chain. However, brand licensing contracts differ insofar as the brand owner/principal reaps profits from both the parent brand and the extension product - profits that, as argued above, are intertwined with the direct and reciprocal effects. As a consequence, an optimal contract needs to not only correct for the misalignment of incentives between partners in the agency relationship, but also govern the impact of the reciprocal effect on brand value. 


\section{The model}

\subsection{Framework}

In order to extend its brand to a new product, a brand owner can choose from two alternative business models: in-house (or internal) development or brand licensing. The former requires the (costly) acquisition of the resources and skills needed to develop and market the extension, but allows the firm to retain complete control over the extension project. The latter involves contracting with a separate firm and establishing a licensor-licensee relationship.

The brand owner reaps profits from both established assets (the "value" or "equity" of the brand) and the new asset (the extension product). In order to preserve a focus on this essential choice and its possible contractual terms, we will assume that the brand's whole value is entirely appropriated by the brand owner. With in-house development, the brand owner wholly reaps the profits from the extension product. With licensing, by contrast, both parties share the profits from the extension product according to the terms of their licensing contract. Brand value, as well as the consumers' willingness to pay for the extension product, depend on costly development and promotion activities made by the firm(s). In particular, the brand owner makes costly investments to create and maintain brand value, which positively affect the profits from both the brand and the extension product. All else being equal, consumers' willingness to pay for the extension increases with their "general appreciation" for the brand, but the extension itself also requires specific investments in order to foster people's willingness to pay for the product itself. In short, the effort exerted on the extension product generates a reciprocal effect on the value of the brand. Following the empirical literature, we assume that the magnitude of this effect depends on consumers' perceived dissimilarity between the extension product and the brand: All else being equal, a larger dissimilarity dampens the reciprocal effect. In the case of in-house development, we posit that this reciprocal effect is positive due to the brand owner's knowledge of the brand's characteristics. In the case of licensing, however, we presume the reciprocal effect can be either positive (brand enhancement) or negative (brand dilution). Under licensing, both the efforts of the brand owner and of the licensee are not contractible, which results in a double-sided moral hazard problem. The brand owner must therefore propose an incentivizing contract to the licensee.

It is worth remarking here that while the brand owner considers the (positive) effect of its nurturing on the extension product (and the related positive reciprocal effect on brand value under internal development), under brand licensing the licensee does not internalize the reciprocal effect of its activities on the value of the brand. Therefore, in the case of brand licensing, the reciprocal effect has the characteristics of an externality on brand value. Clearly, the licensing contract influences the effort the licensee is willing to exert, which the brand owner can then leverage to indirectly control this externality. Figure 1 depicts the relationships between brand owner and licensee in our model. The red and blue boxes represent the assets that generate revenue for the brand owner and licensee, respectively, while the signs on the dashed arrows represent the sign of the effort on the specific asset. 


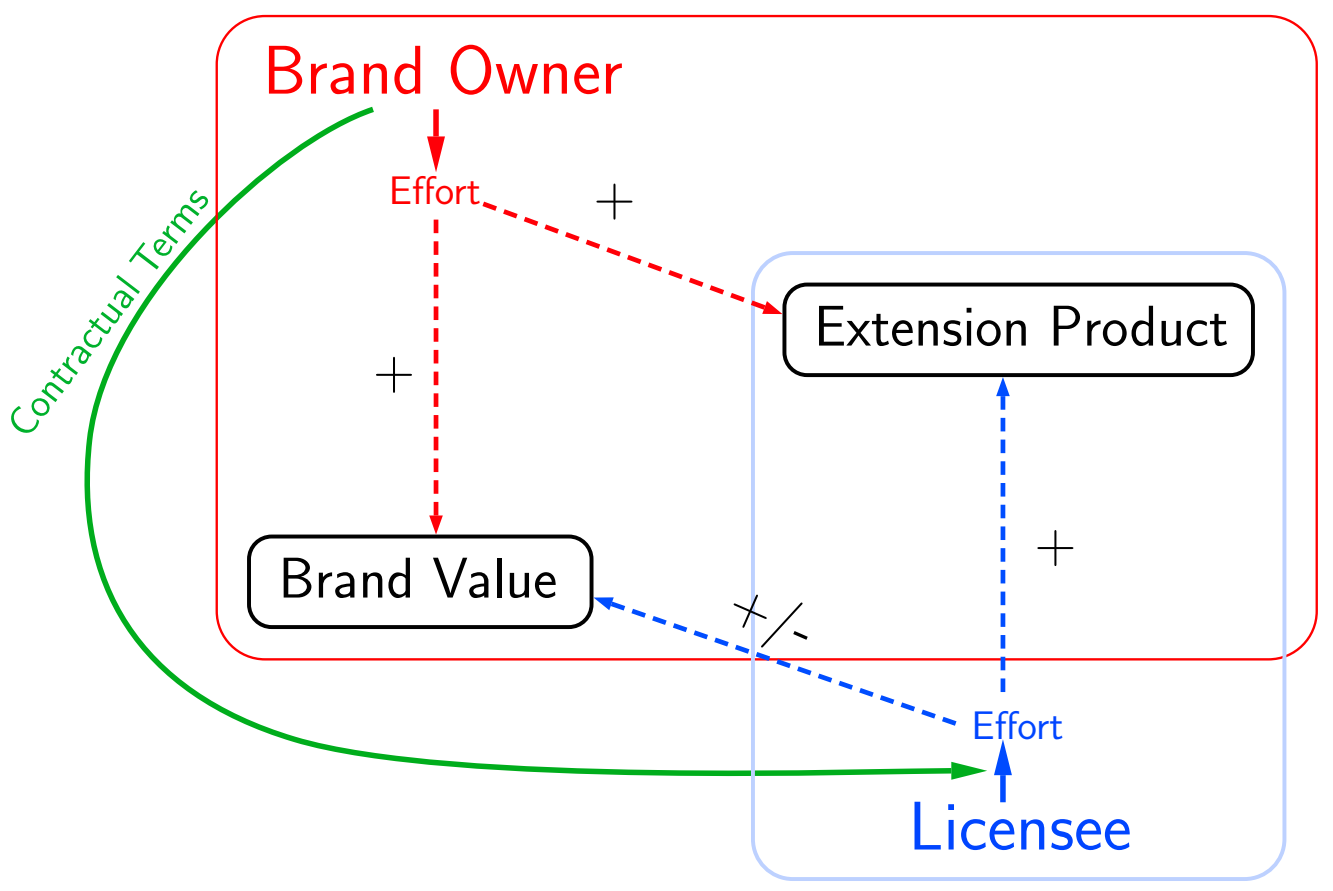

Figure 1: Dashed arrows represent the effort.

The trade-off between in-house development and brand licensing can thus be summarized as follows: Under in-house development, the brand owner can perfectly monitor each production phase (and therefore exert the efficient level of effort), but it needs to sustain high costs since the brand extension's market is more unproven than that of the core brand. Under brand licensing, the brand owner can sidestep this (extra) cost by selecting an experienced licensee, but this requires an incentivizing licensing contract that can generate inefficiencies and possibly expose the brand to a negative reciprocal effect, thereby diluting its value.

To formally navigate this trade-off, and characterize the optimal licensing contract, we arrange and solve a dynamic game involving the brand owner and a potential licensee.

\subsection{Structure of the game}

In the initial stage, the brand owner first decides whether to proceed with brand licensing or inhouse development. Under brand licensing, we assume that the brand owner has full bargaining power in designing the contract and makes a take-it-or-leave-it offer to the licensee. This is in line with observed contracts, as the firm owns and controls the intellectual property. The timing of the licensing sub-game is as follows:

1. The brand owner makes a take-it-or-leave-it contractual offer to the licensee.

2. The licensee accepts or rejects the offer. In case of rejection, the game ends. In case the licensee accepts, the sub-game moves to stage 3 .

3. The brand owner and the licensee simultaneously set effort levels. 
4. The licensee decides how much to produce in the extension product market.

5. Demand and profits are realized.

Under in-house development no actual (sub-)game is played, and the sequence of actions is the following.

1. The brand owner decides how much effort to exert.

2. The brand owner decides how much to produce in the extension product market.

3. Demand and profits are realized.

We look for Subgame Perfect Nash Equilibria of the preceding game. Figure 2 represents the timing of the game.

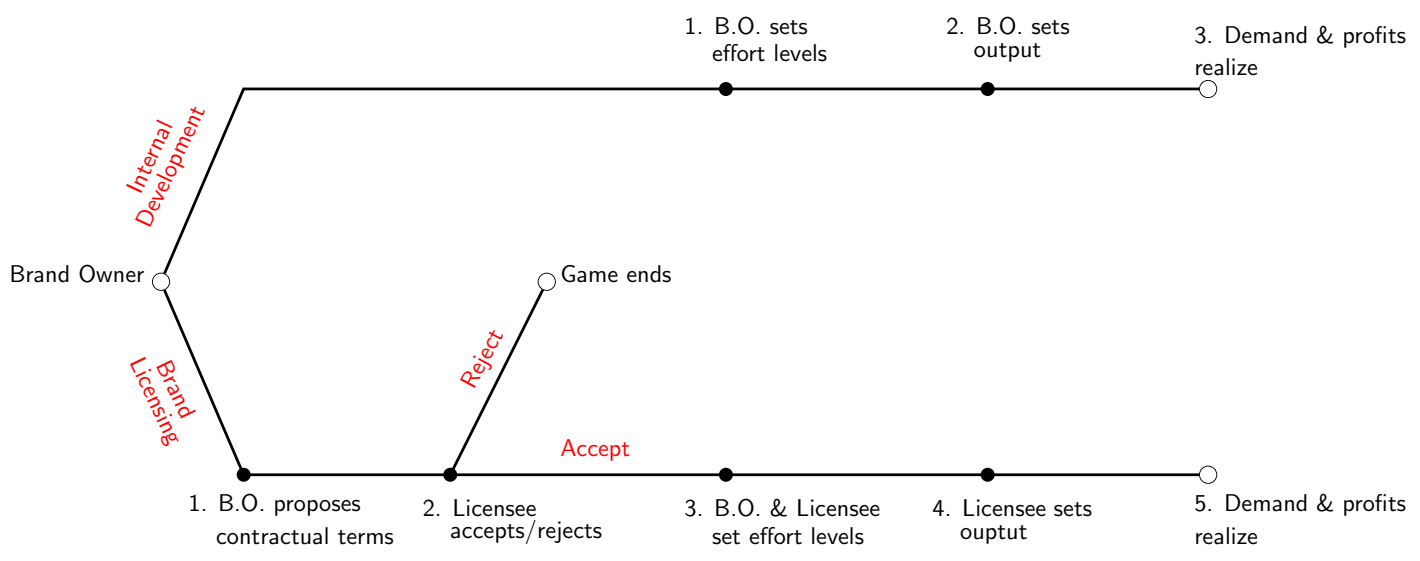

Figure 2: Timing of the game.

\subsection{Fundamentals of the model}

In order to focus solely on the choice between in-house and licensing, we assume that, in either case, there is no market competition for the extension product (i.e., this market is monopolized). Throughout the analysis, we will hypothesize that the costs of production, both for the brand owner and the licensee, are nil. ${ }^{6}$

This will allow us to clearly pin down the features of the licensing contract and the trade-off between brand licensing and in-house production. We model the demand of the extension product as linear: $P(q, \theta)=\theta-q$, with $\theta=e_{b}+e_{j}$, with $j \in\{\ell, i\}$, where $e_{b}$ is the effort of the brand owner in maintaining/improving the value of the brand, $e_{\ell}$ (res. $e_{i}$ ) is the extension product demandenhancing effort exerted by the licensee (res. brand owner) in case of brand licensing (res. in-house development). Last, $q$ is the quantity of the extension product. Exerting effort is costly, and

\footnotetext{
${ }^{6}$ This is an innocuous assumption as long as the actual production costs of the brand owner and the licensee are similar. In cases where they diverge by a relevant amount, a further force would be at work that reduces the interest of the licensing agreement if the costs of the licensee exceed those of the brand owner or the interest of in house development, in the opposite case.
} 
we posit that the associated cost function is convex, implying decreasing returns to scale both in nurturing brand equity and in promoting the extension product. Here we also assume that, for the same increase in the value of the extension product, the cost borne by the brand owner is always larger than it is for the licensee. In formal terms we assume the following:

Assumption 1 (A.1). $c_{b}\left(e_{b}\right)=e_{b}^{2}, c_{\ell}\left(e_{\ell}\right)=e_{\ell}^{2}$ and $c_{i}\left(e_{i}\right)=\beta e_{i}^{2}$, with $\beta>1$.

The parameter $\beta$ measures the inefficiency of the brand owner, relatively to the licensee, in developing the extension: a higher $\beta$ implies a larger cost, hence a larger inefficiency.

The value of the brand, denoted by $R$, is affected by the brand owner's direct efforts in promoting and maintaining it. However, given the above discussion, we also assume that the effort exerted in fostering consumers' willingness to pay for the extension product has a feedback effect on the value of the parent brand. This effect becomes weaker the more that consumers perceive dissimilarity between the extension and the products that characterize the brand (Keller and Aaker, 1992). ${ }^{7}$ Let $\alpha \geq 0$ be the dissimilarity parameter (as $\alpha$ grows, the extension becomes more and more dissimilar from the brand). Then, under in-house development, the brand value is:

$$
R_{i}\left(e_{b}, e_{i} ; \alpha\right)=e_{b}+\frac{1}{1+\alpha} e_{i}
$$

We assume that, when the brand owner develops the extension internally, it always achieves a nonnegative feedback effect on brand equity through its effort to promote the extension product (i.e., there is always brand enhancement). The brand owner, though less efficient than the (potential) licensee, is always able to identify and implement activities that yield a positive feedback effect, thus boosting brand value. Still, the feedback effect weakens as the dissimilarity increases: Intuitively, if consumers perceive the extension product as far removed from the brand, then they will be less apt to transfer their perceptions from one to the other.

If the brand owner instead decides to extend the brand through licensing, it loses full control over the extension process. As a result, the extension may produce either brand dilution or brand enhancement. In either case, the magnitude of the effect still depends on the dissimilarity between the brand and the extension product. We model this by considering the following functional form:

$$
R_{\ell}\left(e_{b}, e_{\ell} ; \gamma, \alpha\right)=e_{b}+\frac{\gamma}{1+\alpha} e_{\ell}
$$

Under brand licensing, the licensee's effort is filtered by the function $\frac{\gamma}{1+\alpha}$. As with in-house development, the feedback effect becomes weaker as the extension product and brand become more dissimilar. In addition, the effort of the licensee influences the value of the core product through the parameter $\gamma \in[-1,1]$, which represents the magnitude and sign of the feedback effect. Contrary

\footnotetext{
${ }^{7}$ Under this assumption, if -say- Ferrari extends its brand to produce baseball caps with the Ferrari logo on them, this product fully benefits from the reputation and prestige of Ferrari. Yet, whatever its sign, the reciprocal effect on the value of the brand is "low" because of the large dissimilarity between caps and luxury sports cars. The same full positive direct effect would be present if the extension involved small electric urban cars. However, in this case, the feedback effect would be larger than that of caps because consumers would perceive this second extension as closer to sports cars.
} 
to in-house development, the effort exerted by the licensee may have either a positive or negative effect on the value of the core product. Specifically, there is brand dilution when $\gamma<0$ and brand enhancement when $\gamma>0$. Both of these effects become weaker as the licensed product and the brand become more dissimilar. ${ }^{8}$ With our framework established, we will analyze the two business models - starting with licensing.

\subsection{Brand licensing}

\subsubsection{Profits}

During the first stage of the game, we assume that the brand owner licenses the brand to a licensee and thus formally becomes a licensor. If the two firms cannot observe each other's effort, then they cannot implement first-best effort levels. As a consequence, the brand owner must propose an incentivizing contract to the licensee. We assume the contract $C$ offered by the brand owner takes the form of a two-part tariff composed of a royalty rate per-unit, $s$, and a fixed fee, $F$ such that $C=\{s, F\} \cdot{ }^{9}$

The licensee's profits are given by:

$$
\pi_{\ell}\left(q, e_{b}, e_{\ell}, C\right)=\underbrace{\left[P\left(q ; e_{b}, e_{\ell}\right)-s\right] \times q-F}_{\begin{array}{c}
\text { Revenues from ext. prod. sales } \\
\text { net of licensing fees }
\end{array}}-\underbrace{e_{\ell}^{2}}_{\begin{array}{c}
\text { Extension product } \\
\text { development cost }
\end{array}}
$$

The licensee reaps profits exclusively from selling the extension product and pays $s$ on each unit sold to the brand owner in addition to a fixed fee, $F$, as agreed upon in the licensing contract.

The brand owner's profits are given by the following expression:

$$
\pi_{b}\left(e_{b}, e_{\ell}, C\right)=\underbrace{R_{\ell}\left(e_{b}, e_{\ell} ; \gamma, \alpha\right)}_{\text {Brand value }}+\underbrace{s \times q+F}_{\begin{array}{c}
\text { Revenue from } \\
\text { licensing contract }
\end{array}}-\underbrace{e_{b}^{2}}_{\begin{array}{c}
\text { Brand value } \\
\text { nurturing cost }
\end{array}} .
$$

The brand owner has two streams of profits: the returns from brand value and the payment for licensing the extension product, which include both a share of quantity sold in that market, $s \times q$, and the fixed fee, $F$.

\subsubsection{Equilibrium}

Optimal quantity. Applying backward induction, we first determine the optimal quantity in the extension product market as set by the licensee. Maximization of $\pi_{\ell}(\cdot)$ with respect to $q$ returns:

$$
q\left(e_{b}, e_{\ell}, s\right)=\frac{1}{2}\left(e_{b}+e_{\ell}-s\right)
$$

\footnotetext{
${ }^{8}$ It should be said that full brand enhancement $\gamma=1$ corresponds to the feedback effect level under in-house development.

${ }^{9}$ This two-part tariff is standard in licensing contracts, as illustrated by Raugust (2012), and it has also been shown that it is an optimal contractual schedule in models with double-sided moral hazard (Choi, 2001).
} 
As expected, the quantity sold by the licensee increases the effort exerted by both the licensee itself $\left(e_{\ell}\right)$ and the brand owner $\left(e_{b}\right)$, and decreases the royalty rate, which acts as a variable production cost.

By plugging that quantity back into the licensee's profits, we obtain:

$$
\pi_{\ell}\left(e_{b}, e_{\ell}, C\right)=\frac{1}{4}\left(e_{b}+e_{\ell}-s\right)^{2}-F-e_{\ell}^{2} .
$$

In a similar manner, by substituting the optimal quantity back into the brand owner's profit, we get:

$$
\pi_{b}\left(e_{b}, e_{\ell}, C\right)=e_{b}+\frac{\gamma}{1+\alpha} e_{\ell}+\frac{s}{2}\left(e_{b}+e_{\ell}-s\right)+F-e_{b}^{2}
$$

Optimal effort levels. We now characterize the optimal effort levels of the brand owner and licensee, which are defined as follows. ${ }^{10}$

$$
e_{b}(s)=\arg \max _{e_{b}} \pi_{b}\left(e_{b}, e_{\ell}, C\right), \quad e_{\ell}(s)=\arg \max _{e_{\ell}} \pi_{\ell}\left(e_{b}, e_{\ell}, C\right)
$$

By simultaneously solving the two first-order conditions, we obtain:

$$
e_{b}(s)=\frac{1}{2}+\frac{s}{4}, \quad e_{\ell}(s)=\frac{1}{6}-\frac{s}{4}
$$

It is easy to see that $e_{b}(s)$ is increasing in $s$, whereas the opposite holds for $e_{\ell}(s)$. This is intuitive: All else being equal, an increase in the royalty rate increases (res. decreases) the profit of the brand owner (licensee), and thus makes this agent more (less) willing to put effort into promoting the brand (the extension product). In our analysis, $\theta$ and $R$ are modelled such that the two effort levels are additive; therefore the marginal effect is independent of each other's effort levels. Lastly, and for future reference, the linear-additive structure of $\theta$ implies that the total effort on the extension product is independent on the royalty rate and equal to $e_{b}(s)+e_{\ell}(s)=\frac{2}{3} \cdot{ }^{11}$

Substituting the optimal effort levels back into $\pi_{\ell}\left(e_{b}, e_{\ell}, C\right)$ and $\pi_{b}\left(e_{b}, e_{\ell}, C\right)$, we get

$$
\pi_{\ell}(C)=\frac{1}{48}(2-3 s)^{2}-F, \quad \pi_{b}(C)=\frac{1}{48}\left[12+16 s-27 s^{2}+4 \frac{\gamma}{1+\alpha}(2-3 s)\right]+F .
$$

Optimal licensing contract. Because the brand owner is entitled to propose a take-it-or-leaveit contract to the licensee, the licensee can only accept or reject the offer. Thus, the proposed contractual terms will be such that the licensee is left indifferent between accepting or not, given its outside option. To keep the analysis simple, we normalize this outside option to zero, which implies that the licensee's profits are also zero in the optimal contract. ${ }^{12}$ Consequently, in the

\footnotetext{
${ }^{10}$ It is a matter of simple calculations to ascertain that the profit functions are always concave with regard to each firm's own effort.

${ }^{11}$ Intuitively, this means that the brand owner, when setting the optimal royalty rate, fully internalizes its effect on the licensee's effort.

${ }^{12}$ Obviously, allowing for a positive outside option for the licensee would entail a reduction in the profitability of the licensing contract for the brand owner, which would, in turn, make the licensing strategy less appealing, all else
} 
optimal contract, the brand owner appropriates all the licensee's surplus - thereby, the fixed part of the licensing tariff is $F(s)=\frac{1}{48}(2-3 s)^{2}$. The brand owner's profit in this case would be:

$$
\pi_{b}(s, F(s))=\frac{1}{24}\left[8+2 s-9 s^{2}+2 \frac{\gamma}{1+\alpha}(2-3 s)\right] .
$$

It is a matter of simple calculations to maximize the last expression with respect to $s$ to find the optimal royalty rate: ${ }^{13}$

$$
s(\alpha, \gamma)=\frac{1}{3}\left(\frac{1}{3}-\frac{\gamma}{(1+\alpha)}\right) \equiv s^{*}
$$

By plugging $s^{*}$ back into $F(s)$, we obtain $F(\alpha, \gamma)=\frac{[5(1+\alpha)+3 \gamma]^{2}}{432(1+\alpha)^{2}} \equiv F^{*}$. We can then state the following:

Proposition 1. Under double-sided moral hazard, the optimal two-part licensing contract is

$$
C^{*}=\left\{s^{*}, F^{*}\right\}=\left\{\frac{1}{3}\left(\frac{1}{3}-\frac{\gamma}{(1+\alpha)}\right), \frac{[5(1+\alpha)+3 \gamma]^{2}}{432(1+\alpha)^{2}}\right\} .
$$

A first ancillary result is easily obtained.

Corollary 1. The optimal royalty rate $s^{*}$ is

(i) Decreasing in the reciprocal effect: $\frac{\partial s^{*}}{\partial \gamma}<0$,

(ii) Negative for $\gamma>\frac{1+\alpha}{3}$ and positive otherwise,

(iii) Decreasing in the dissimilarity $\alpha$ in the case of negative reciprocal effect $\left(\frac{\partial s^{*}}{\partial \alpha}<0 \quad \forall \gamma \in\right.$ $[-1,0))$ and increasing in the dissimilarity in the case of positive reciprocal effect $\left(\frac{\partial s^{*}}{\partial \alpha}>\right.$ $0 \quad \forall \gamma \in(0,1])$.

In order to understand the forces that shape the optimal royalty rate (and thus Corollary 1), it is useful to keep in mind that the licensing contract is designed so that the brand owner appropriates all the licensee's generated surplus through the fixed fee, which leaves the royalty rate to be the sole factor that shapes the effort and output incentives. This said, let us consider that, at $F(s)$, equation (2) can be re-written as:

$$
\pi_{b}\left(e_{b}(s), e_{\ell}(s), s, F(s)\right)=R_{\ell}\left(e_{b}(s), e_{\ell}(s) ; \alpha, \gamma\right)+P\left(q, e_{b}(s), e_{\ell}(s)\right) \times q(s)-e_{b}(s)^{2}-e_{\ell}(s)^{2} .
$$

Taking the first order derivative with respect to $s$, we get (omitting the arguments for the sake of readability)

$$
\frac{\partial \pi_{b}}{\partial s}=\frac{\partial R_{\ell}}{\partial e_{b}} \frac{\partial e_{b}}{\partial s}+\frac{\partial R_{\ell}}{\partial e_{\ell}} \frac{\partial e_{\ell}}{\partial s}+q \times\left(\frac{\partial P}{\partial e_{b}} \frac{\partial e_{b}}{\partial s}+\frac{\partial P}{\partial e_{\ell}} \frac{\partial e_{\ell}}{\partial s}\right)+P \times \frac{\partial q}{\partial s}-2 e_{b} \frac{\partial e_{b}}{\partial s}-2 e_{\ell} \frac{\partial e_{\ell}}{\partial s} .
$$

being equal.

${ }^{13}$ The profit function $\Pi_{B}(s)$ is always convex in $s$ because $\pi_{b}^{\prime \prime}(s, F(s))=-\frac{3}{4}$. 
Let $\frac{\partial R_{\ell}}{\partial e_{b}} \equiv R^{\prime}$, then $\frac{\partial R_{\ell}}{\partial e_{\ell}} \equiv \frac{\gamma}{1+\alpha} R^{\prime}$, and $\frac{\partial P}{\partial e_{b}}=\frac{\partial P}{\partial e_{\ell}} \equiv P^{\prime}$. We get:

$$
\frac{\partial \pi_{b}}{\partial s}=\left(\frac{\partial e_{b}}{\partial s}+\frac{\gamma}{1+\alpha} \frac{\partial e_{\ell}}{\partial s}\right) R^{\prime}+\left(q \times P^{\prime}-2\right)\left(\frac{\partial e_{b}}{\partial s}+\frac{\partial e_{\ell}}{\partial s}\right)+P \times \frac{\partial q}{\partial s}-2 e_{b} \frac{\partial e_{b}}{\partial s}-2 e_{\ell} \frac{\partial e_{\ell}}{\partial s} .
$$

Further, in our model $R^{\prime}=P^{\prime}=1$ and $\frac{\partial e_{b}}{\partial s}=-\frac{\partial e_{\ell}}{\partial s} \equiv e^{\prime}>0$, which, together with (7), imply that (14) boils down to:

$$
\frac{\partial \pi_{b}}{\partial s}=\underbrace{e^{\prime}\left(1-\frac{\gamma}{1+\alpha}\right)}_{\substack{\text { Brand promotion effect } \\ \geq 0}}+\underbrace{P \times \frac{\partial q}{\partial s}}_{\text {Sales reduction effect }}+\underbrace{\left[-e^{\prime}\left(\frac{2}{3}+s\right)\right]}_{\substack{\text { Effort cost effect } \\<0}} .
$$

The first term in (15) reflects a change in brand value stemming from an increase in the royalty rate; we refer to this as the Brand Promotion Effect (BPE). As the royalty rate increases, the brand owner is willing to put more effort into promoting the brand because, all else being equal, it can obtain higher licensing profits. At the same time, the licensee is investing less to develop the extension product, which has a feedback effect on the brand value (see (7)). However, the impact of this effect depends on the sign and size of the reciprocal effect $(\gamma)$, as well as the dissimilarity between the brand and the extension product $(\alpha)$. In the case of brand enhancement $(\gamma>0)$, a higher royalty rate hinders the licensee's effort, thus reducing the positive spillover on brand value. In the case of brand dilution $(\gamma<0)$, a higher royalty rate reduces the effort of the licensee, which helps dampen the negative externality on the parent brand. In either case, the overall magnitude of the effect is reduced (res. increased) as the dissimilarity between the extension and brand grows larger (smaller). The assumptions on $\gamma$ and $\alpha$ imply that $\frac{\gamma}{1+\alpha} \in[-1,1]$ : Therefore, the overall effect of an increase of $s$ on brand value is non-negative. In sum, the BPE pushes the licensor to increase the royalty rate.

We label the second term in (15) Sales Reduction Effect (SRE). As indicated above, a higher $s$ fosters more effort from the brand owner while hindering the licensee. The two effects cancel each other out in determining the maximum willingness to pay for the extension product: As noted above, $\theta=e_{b}(s)+e_{\ell}(s)=\frac{2}{3}$, so that a change in the royalty value has no effect on that variable. Yet, a rise in the royalty rate does affect the extension product's market, amounting to an increase in the licensee's marginal production cost. The obvious consequence is that increasing the royalty rate reduces sales of the extension product, and thus the licensee's profit. Eventually, this translates into a lower fixed fee that can be contractually imposed by the brand owner. The SRE clearly pushes the licensor to reduce the royalty rate.

We refer to the third term in (15) as the Effort Cost Effect (ECE). This force arises from an increase in $s$, through its effect on the optimal effort levels, and affects the effort costs borne by the firms. Now, recall that the licensee's profit is completely appropriated by the licensor through the fixed fee $F(s)$, ultimately entailing that the brand owner - besides assessing how a variation in $s$ impacts its own cost - internalizes the effect of a variation of the royalty rate on the cost borne by the licensee. In particular, a higher $s$ spurs an increase in the brand owner's effort and thus its 
cost, which then reduces its profit. This simultaneously lowers the licensee's effort and cost, which then increases its profit. The ECE is the result of these two forces and is negative, meaning that an increase in $s$ raises the cost of effort for the licensor more that it reduces that for the licensee, which pushes the brand owner to reduce $s$.

Having disentangled the components of an increase in the royalty rate, let us now comment on Corollary 1. Point (i), i.e., $\frac{\partial s^{*}}{\partial \gamma}<0$, is explained by the fact that, as $\gamma$ increases, the magnitude of the BPE is reduced, while those of the SRE and ECE are unaffected. In other words, the forces that drive down the royalty rate usurp the BPE. With a strong negative reciprocal effect ( $\gamma$ "close" to -1 ) the licensee's effort toward the extension product has a strong negative impact on brand value. Consequently, the brand owner sets a high royalty rate, which has a dual impact: On one hand, it limits the damage inflicted to brand value; on the other hand, it spurs the licensor's own effort, thereby countervailing the reduction in $e_{\ell}$ following the increase in $s^{*}$. This choice also increases (decreases) the cost borne by the brand owner (licensee). As $\gamma$ rises, the negative reciprocal effect diminishes and eventually becomes positive. As a consequence, the brand owner has less need to curb the licensee's effort and can lower the optimal royalty rate, which also entails a reduction in the overall costs generated by the two firms' efforts. Interestingly, this effect, which pushes $s^{*}$ down, can be strong enough to make the optimal royalty rate negative, as remarked by point (ii) of Corollary 1. This happens if $\gamma>\frac{1+\alpha}{3}$ : the brand owner effectively subsidizes the licensee's efforts via a negative royalty rate in order to exploit a sufficiently large, positive reciprocal effect. This boosts both the sales of the extension product - via a reduction in the licensee's marginal production cost - and the brand value. Clearly, the licensee's costs increase, but this is more than compensated by a reduction in the brand owner's costs. It is worth highlighting that achieving a subsidizing royalty rate requires that $\alpha<2$ : The dissimilarity between the extension product and the parent brand has to be "limited" (i.e., consumers must perceive the two as close enough) in order to make the impact of the "large", positive reciprocal effect strong enough to trigger a negative royalty rate. Lastly, we consider point (iii) of Corollary 1. Dissimilarity has a negative effect on $s^{*}$ under brand dilution and a positive one under brand enhancement. Under brand dilution, a higher dissimilarity weakens the impact of the negative externality on brand value, thus reducing the licensor's incentive to restrain the licensee's effort. By lowering the optimal royalty rate, the brand owner facilitates an increase in sales of the extension product, which leads to an increase in the licensing revenues, while also dampening the negative impact on brand value. Furthermore, a reduction in the royalty reduces (increases) the brand owner's (licensee's) effort and therefore its costs, resulting in a lower value for $F(s)$. Under brand enhancement, the reasoning is the opposite: A larger dissimilarity weakens the positive impact of the licensee's effort on brand value. By increasing $s$, the brand owner lowers the licensee's effort (and thus cost), which amounts to a larger $F(s)$ and, simultaneously, an increase in its own effort, which has a direct impact on brand value. We can now state:

Corollary 2. The optimal fixed fee $F\left(s^{*}\right)$ is

(i) Increasing in the reciprocal effect $\gamma: \frac{\partial F\left(s^{*}\right)}{\partial \gamma}>0$, 
(ii) Increasing in the dissimilarity $\alpha$ in the case of negative reciprocal effect $\left(\frac{\partial F\left(s^{*}\right)}{\partial \alpha}>0 \quad \forall \gamma \in\right.$ $[-1,0))$ and decreasing in the dissimilarity in the case of positive reciprocal effect $\left(\frac{\partial F\left(s^{*}\right)}{\partial \alpha}<\right.$ $0 \quad \forall \gamma \in(0,1])$,

(iii) Always positive.

First of all, remember that the fixed fee equals the profit obtained by the licensee from the sales of the extension product, gross of the fee itself. That said, the analysis of the behavior of $s^{*}$ relative to $\gamma$ and $\alpha$ helps to explain Corollary 2. As for point $(i)$, letting $\gamma$ increase from a low starting value has the effect of lowering the optimal royalty rate; this ultimately increases the sales of the extension product, the profit of the licensee and, eventually, the fixed fee demanded by the licensor, which explains point $(i)$ of the foregoing Corollary. Point $(i i)$ is explained on similar grounds: As a decrease in dissimilarity reduces the optimal royalty rate (like in the case of brand dilution), a subsequent increase in $\alpha$, through its royalty-reducing effect, induces an increase in the licensee's profit and thereby of the fixed fee, like in the case of an increase in $\gamma$. The mirror reasoning explains the second part of point $(i i)$ : an increase in dissimilarity (as in the case of brand enhancement) boosts the optimal royalty rate, which reduces the licensee's sales and profits, and thus the optimal fixed fee charged by the licensor. As a last remark, the optimal fixed fee is always positive, unlike the optimal royalty rate. This is intuitive: In a two-part tariff contract, the fixed fee is solely intended to extract the agent's surplus, which relegates the incentivizing role to the royalty rate.

Having characterized and discussed the optimal contract, we can now plug the values of $C^{*}$ back into the relevant variables of the model and obtain the following:

Corollary 3. At the optimal brand licensing contract $C^{*}$,

(i) The optimal efforts are

$$
e_{b}^{*} \equiv e_{b}\left(s^{*}\right)=\frac{19(1+\alpha)-3 \gamma}{36(1+\alpha)}, \quad e_{\ell}^{*} \equiv e_{\ell}\left(s^{*}\right)=\frac{5(1+\alpha)+3 \gamma}{36(1+\alpha)},
$$

(ii) The quantity sold on the extension market is

$$
q^{*}=\frac{5(1+\alpha)+3 \gamma}{18(1+\alpha)}
$$

(iii) The profits of the firms are

$$
\pi_{b}^{*} \equiv \pi_{b}\left(C^{*}\right)=\frac{30(1+\alpha) \gamma+73(1+\alpha)^{2}+9 \gamma^{2}}{216(1+\alpha)^{2}}, \quad \pi_{\ell}^{*} \equiv \pi_{\ell}\left(c^{*}\right)=0 .
$$

Simple computation reveals that all the above variables are positive for all admissible parameter 
constellations. Furthermore, it is easily verified that:

$$
\frac{\partial e_{b}^{*}}{\partial \gamma}=-\frac{1}{12(\alpha+1)}<0, \quad \frac{\partial e_{b}^{*}}{\partial \alpha}=\frac{\gamma}{12(\alpha+1)^{2}} \gtreqless 0 \Leftrightarrow \gamma \gtreqless 0,
$$

and

$$
\frac{\partial e_{\ell}^{*}}{\partial \gamma}=\frac{1}{12(\alpha+1)}>0, \quad \frac{\partial e_{\ell}^{*}}{\partial \alpha}=-\frac{\gamma}{12(\alpha+1)^{2}} \gtreqless 0 \Leftrightarrow \gamma \lesseqgtr 0 .
$$

Also

$$
\frac{\partial \pi_{b}^{*}}{\partial \gamma}=\frac{5(1+\alpha)+3 \gamma}{36(1+\alpha)^{2}}>0, \quad \frac{\partial \pi_{b}^{*}}{\partial \alpha}=-\gamma \frac{5(1+\alpha)+3 \gamma}{36(1+\alpha)^{2}} \gtreqless 0 \Leftrightarrow \gamma \lesseqgtr 0 .
$$

The effort of the brand owner (res. licensee) decreases (increases) with the reciprocal effect $\gamma$ for given $\alpha$ and increases (decreases) with the dissimilarity for given $\gamma$. In addition, the profit of the brand owner, at the equilibrium of the licensing subgame, increases with $\gamma$ for given dissimilarity because, as pointed out above (see the discussion of Corollaries 1 and 2), a larger $\gamma$ increases the positive effect on brand value as well as the fixed fee $F$. A similar reasoning applies for an increase in $\alpha$ in the case of brand dilution, which mirrors the case of an increase in dissimilarity in the presence of brand enhancement. To complete our comments, we observe that, while the total effort under brand licensing is constant $e_{b}^{*}+e_{\ell}^{*}=\frac{2}{3}, \alpha$ and $\gamma$ dictate how the firms apportion this total effort in the optimal contract.

\subsubsection{Comparison with complete contract}

It is instructive to compare the outcomes of the licensing game with those under complete contracts. In this latter case, effort is contractible; consequently, the brand owner will propose a contract that specifies the desired effort levels and extracts all the surplus of the relationship through a fixed fee. ${ }^{14}$ Here we will limit ourselves to reporting the main differences relative to the incomplete contract analyzed so far, the details of the calculations being relegated to Appendix A. As expected, the optimal effort of the brand owner is always larger under a complete contract than under an incomplete one, but this is not true for the licensee. In fact, the first-best effort of the licensee falls short of the second-best one for $\gamma<-\frac{1+\alpha}{5}$, which is a non-empty region under A.1 for $\alpha<5$. The intuition is clear: When the reciprocal effect is negative enough and dissimilarity is small, the brand owner contractually reduces the licensee's effort in order to limit brand dilution. This behavior can reach the point where the licensee is contractually bound to exert no effort at all. This is particularly the case when $\gamma<-\frac{1+\alpha}{2}$, which requires $\alpha<2$. In this parameter region, the licensor's effort is constant and equal to the aggregate one under incomplete contracts. It is interesting to notice that, under incomplete contracts, the brand owner cannot contractually force the licensee to refrain from developing the extension, and must therefore rely on the royalty rate to curb effort provision. Under a complete contract, as long as the licensee is expected to exert a positive effort, the aggregate effort is larger than that under an incomplete contract. The two aggregate effort levels coincide when, in the optimal complete contract, the licensee is bound to

\footnotetext{
${ }^{14}$ See Choi (2001).
} 
exert no effort.

\subsection{In-house development}

Let us now analyze the case where the brand owner instead pursues in-house development. Here, there is clearly no contract involved; rather, the brand owner selects the optimal effort levels needed to achieve a desired sales quantity for the extension product. However, see Assumption A.1, the brand owner is less efficient (by a parameter $\beta>1$ ) than the (potential) licensee in carrying out the development and promotion of the extension product. Granted, we also assume that the brand owner's efficiency in nurturing brand value does not vary relative to the brand licensing case. ${ }^{15}$

\subsubsection{Profits}

In case of internal development, the profit accruing to the brand owner is as follows:

$$
\pi_{i}\left(q, e_{b}, e_{i}\right)=\underbrace{R_{i}\left(e_{b}, e_{i}, \alpha\right)}_{\text {Brand value }}+\underbrace{P\left(q ; e_{b}, e_{i}\right) \times q}_{\begin{array}{c}
\text { Profit from } \\
\text { extension product }
\end{array}}-\underbrace{e_{b}^{2}}_{\begin{array}{c}
\text { Brand value } \\
\text { nurturing cost }
\end{array}}-\underbrace{\beta e_{i}^{2}}_{\begin{array}{c}
\text { Extension product } \\
\text { development cost }
\end{array}} .
$$

\subsubsection{Equilibrium}

We start by analyzing the brand owner's sales behavior in the extension market, given the effort levels of the previous stage.

Optimal quantity. Maximization of $\pi_{i}(\cdot)$ with respect to $q$ for given $e_{b}$ and $e_{i}$ returns (secondorder conditions are always satisfied):

$$
q\left(e_{b}, e_{i}\right)=\frac{e_{b}+e_{i}}{2}
$$

which can be plugged back into (22) to obtain

$$
\pi_{i}\left(e_{b}, e_{i}\right)=e_{b}+\frac{e_{i}}{1+\alpha}+\frac{\left(e_{b}+e_{i}\right)^{2}}{4}-e_{b}^{2}-\beta e_{i}^{2}
$$

Optimal effort levels. Simultaneous maximization of $\pi_{i}\left(e_{b}, e_{i}\right)$ with respect to $e_{b}$ and $e_{i}$ yields the optimal effort levels in brand value nurturing and extension product development under in house development, which we summarize in the following. ${ }^{16}$

\footnotetext{
${ }^{15}$ In order to avoid burdening the notation, we will not introduce further indices to distinguish between the effort of the brand owner in promoting the brand $\left(e_{b}\right)$ and the quantity of the extension product $(q)$ under brand licensing versus in-house development. We hope to mitigate any confusion by treating the two cases separately.

${ }^{16}$ The Hessian matrix of the maximization problem is $\mathcal{H}=\left(\begin{array}{cc}-3 / 2 & 1 / 2 \\ 1 / 2 & 1 / 2-2 \beta\end{array}\right)$. Direct inspection reveals that the first-order principal minors are negative and simple algebra confirms that $\operatorname{det} \mathcal{H}=-1+3 \beta$ is positive under A.1, which insure the joint concavity of the maximand relative to the maximizers.
} 
Corollary 4. The optimal effort levels under in-house development are:

$$
\hat{e}_{b}=\frac{1}{6}\left[\frac{4+\alpha}{(1+\alpha)(3 \beta-1)}+4\right], \quad \hat{e}_{i}=\frac{4+\alpha}{2(1+\alpha)(3 \beta-1)} .
$$

The optimal in-house effort levels are positive under assumption A.1; it is also straightforward to obtain that

$$
\frac{\partial \hat{e}_{b}}{\partial \beta}=-\frac{4+\alpha}{2(1+\alpha)(3 \beta-1)^{2}}<0, \quad \frac{\partial \hat{e}_{b}}{\partial \alpha}=-\frac{1}{2(1+\alpha)^{2}(3 \beta-1)}<0,
$$

and

$$
\frac{\partial \hat{e}_{i}}{\partial \beta} \equiv-\frac{3(4+\alpha)}{2(1+\alpha)(3 \beta-1)^{2}}<0, \quad \frac{\partial \hat{e}_{i}}{\partial \alpha} \equiv-\frac{3}{2(1+\alpha)^{2}(3 \beta-1)}<0 .
$$

These results are intuitive: On one hand, an increase in the cost of developing the extension (all else being equal) negatively impacts the brand owner's overall profits, thereby reducing its general willingness to invest. On the other hand, a larger distance dampens the positive reciprocal effect stemming from the extension on the product market, again reducing the firm's profits and willingness to invest. Thus, the total effort exerted under in-house development is $\hat{e}_{b}+\hat{e}_{i}=$ $\frac{2(\alpha \beta+\beta+1)}{(\alpha+1)(3 \beta-1)}$. Notably, this total effort is larger than the total under brand licensing, but this is hardly surprising: The double-sided moral hazard problem arising from the latter situation reduces both firms' incentives to invest.

Substituting (25) back into (23) and (24) yields the following:

Corollary 5. Under in-house development of the extension product, at the optimal efforts $\hat{e}_{b}$ and $\hat{e}_{i}$

(i) The quantity sold on the extension market is:

$$
\hat{q} \equiv q\left(\hat{e}_{b}, \hat{e}_{i}\right)=\frac{1+\beta(1+\alpha)}{(1+\alpha)(3 \beta-1)},
$$

(ii) The profit of the brand owner is:

$$
\hat{\pi}_{i} \equiv \pi_{i}\left(\hat{e}_{b}, \hat{e}_{i}\right)=\frac{1}{12}\left[\frac{(4+\alpha)^{2}}{(1+\alpha)^{2}(3 \beta-1)}+4\right] .
$$

As before, computing first-order partial derivatives:

$$
\frac{\partial \hat{q}}{\partial \beta}=-\frac{\alpha+4}{(1+\alpha)(3 \beta-1)^{2}}<0, \quad \frac{\partial \hat{q}}{\partial \alpha}=-\frac{1}{(\alpha+1)^{2}(3 \beta-1)}<0,
$$

and

$$
\frac{\partial \hat{\pi}_{i}}{\partial \beta}=-\frac{(\alpha+4)^{2}}{4(1+\alpha)^{2}(3 \beta-1)^{2}}<0, \quad \frac{\partial \hat{\pi}_{i}}{\partial \alpha}=-\frac{(\alpha+4)}{(\alpha+1)^{3}(3 \beta-1)}<0,
$$

reveals that both the quantity of the extension product and the profit of the brand owner decrease 
in tandem with the firm's cost-inefficiency and the dissimilarity between the extension product and the parent brand. This aligns with our previous analysis: An increase in $\alpha$ or $\beta$ reduces the brand owner's effort and ultimately results in lower profits.

\subsection{Choice of the optimal business strategy}

In the previous sections, we characterized and discussed the optimal licensing contract (and the optimal efforts, sales and profit it induces), as well as highlighted the brand owner's investment and production choices when it opts for in-house development. We are now in a position to analyze the brand owner's optimal choice at the outset of the game - whether to make or license. For the sake of readability, we will distinguish between a relatively cost-efficient brand owner (albeit still less cost-efficient than a potential licensee, i.e., $\beta>1$ ) and a relatively more cost-inefficient brand owner, but discuss their outcomes organically. The proofs are relegated in Appendix B.

Proposition 2. Under Assumption A.1, a cost-efficient brand owner $\left(1<\beta<\frac{19}{3}\right)$

(a) Develops in-house the extension for any dissimilarity level between the core product and the extension market when $\gamma<.2$ or for $\beta<\frac{\gamma(30+\gamma)-3}{12 \gamma^{2}}$ if $\gamma>.2$.

(b) Develops the extension in-house for "small" dissimilarity, licenses it for "intermediate" dissimilarity and reverts to in-house production for "large" dissimilarity when $\frac{\gamma(30+\gamma)-3}{12 \gamma^{2}}<\beta<$ $\frac{96}{9 \gamma^{2}+30 \gamma+1}+\frac{1}{3}$.

(c) Licenses the extension for "small" dissimilarity and develops it in house for "large" dissimilarity when $\frac{96}{9 \gamma^{2}+30 \gamma+1}+\frac{1}{3}<\beta<\frac{19}{3}$.

And

Proposition 3. Under Assumption A.1, a cost-inefficient brand owner $\left(\beta>\frac{19}{3}\right)$

(d) Develops the extension in-house for "small" dissimilarity and licenses it for "large" dissimilarity when $\beta<\frac{96}{9 \gamma^{2}+30 \gamma+1}+\frac{1}{3}$.

(e) Licenses the extension for any dissimilarity when $\beta>\frac{19}{3}$ and $\beta>\frac{96}{9 \gamma^{2}+30 \gamma+1}+\frac{1}{3}$.

Figure 3 depicts the parameter space partition determined by the foregoing Propositions, as well as reports the reciprocal effect (in the case of brand licensing), $\gamma$, on the horizontal axis and the cost-inefficiency of the brand owner (in the case of in-house development), $\beta$, on the vertical axis. Though apparently complex, the qualitative message conveyed follows a recognizable pattern: In-house development is the dominant choice when the brand owner is efficient and the reciprocal effect is either negative or only slightly positive. Similarly, brand licensing is dominant when the brand owner is inefficient and the reciprocal effect is moderately to strongly positive. In the other cases, the optimal choice depends, in a possibly non-linear way, on the degree of dissimilarity between the extension and the brand. That said, we will now detail the intuition underlying the choice of the optimal business model, starting with Proposition 2. 
Case (a) is easily understood. Here the brand owner is relatively cost-efficient $\left(1<\beta<\frac{19}{3}\right)$ and therefore has a "small" incentive to enter a licensing relationship because the (limited) gains arising from the development costs are more than offset by the inefficiency of the incentivizing contract. In addition, in the case of brand dilution, a licensing contract would adversely impact brand value and thereby reduce the profitability of this business model. Hence, the choice toward in-house development. A similar reasoning applies even in the case of brand enhancement: As long as $\gamma$ is small enough, a small positive reciprocal effect only partially compensates for the contractually-driven inefficiencies.

Before delving into case (b), it is useful to comment on case (c). In this region, the brand owner is still relatively cost-efficient, but the reciprocal effect is positive and strong. As a consequence, the brand owner licenses the brand when the dissimilarity is small, thereby boosting the large positive impact on brand value at the cost of entering an inefficient contract. An increase in dissimilarity dampens the positive spillover from the extension onto the brand and increases the relative profitability of in-house development. Thus, that choice is dominant for a "large enough" dissimilarity.

Keeping these ideas in mind, let us now move to region (b). The parameter conditions in this region are intermediate relative to cases (a) and (c): For any given cost inefficiency, $\beta$, the brand enhancement is larger than in (a) but lesser than in (c); for any given level of reciprocal effect, $\gamma$, the cost inefficiency is larger than in (a) but smaller than in (c). Clearly, the first and second effects push the brand owner toward licensing or in-house production, respectively. When the dissimilarity is small, the brand owner prefers to exploit its (relatively small) cost efficiency to avoid entering the contract, thus opting for in-house development. As the dissimilarity increases, the brand owner reduces its effort on the extension market (see equation (27)), as would do the licensee in the same situation (see equation (20)). Yet, it is easy to see that the brand owner's effort on the extension market decreases faster than that of the licensee for $\gamma>0$ and $\beta<\frac{19}{3}$ because of the former's relatively higher cost-inefficiency. As $\alpha$ increases and triggers the shift, the licensing option becomes more profitable than in-house development. Nonetheless, a further increase in $\alpha$ hinders the positive effect of licensing (as happens in region (c)), which makes in-house development preferable again for a "large" dissimilarity.

Let us now turn to Proposition 3. Case (d) is the mirror image of case (c): Here, the brand owner is relatively inefficient in developing the extension, but still prefers this business model when the dissimilarity is small and reciprocal effect is either negative or only slightly positive. Because brand licensing reduces brand value and generates the cost of an inefficient contract, it should be avoided when a small dissimilarity exposes the brand value to a relevant harm (or a tiny enhancement), even at the (large) cost of developing the extension in-house. An increase in the dissimilarity, however, shields the core brand from said harm and thus allows the brand owner to safely license the extension and exploit the licensee's relative cost efficiency. Finally, in case (e), the optimal business model is brand licensing for any dissimilarity level. The intuition is straightforward: Here the reciprocal effect is positive and the brand owner is inefficient, so that the cost of entering an 
inefficient contract is always less than that of developing the extension in-house.

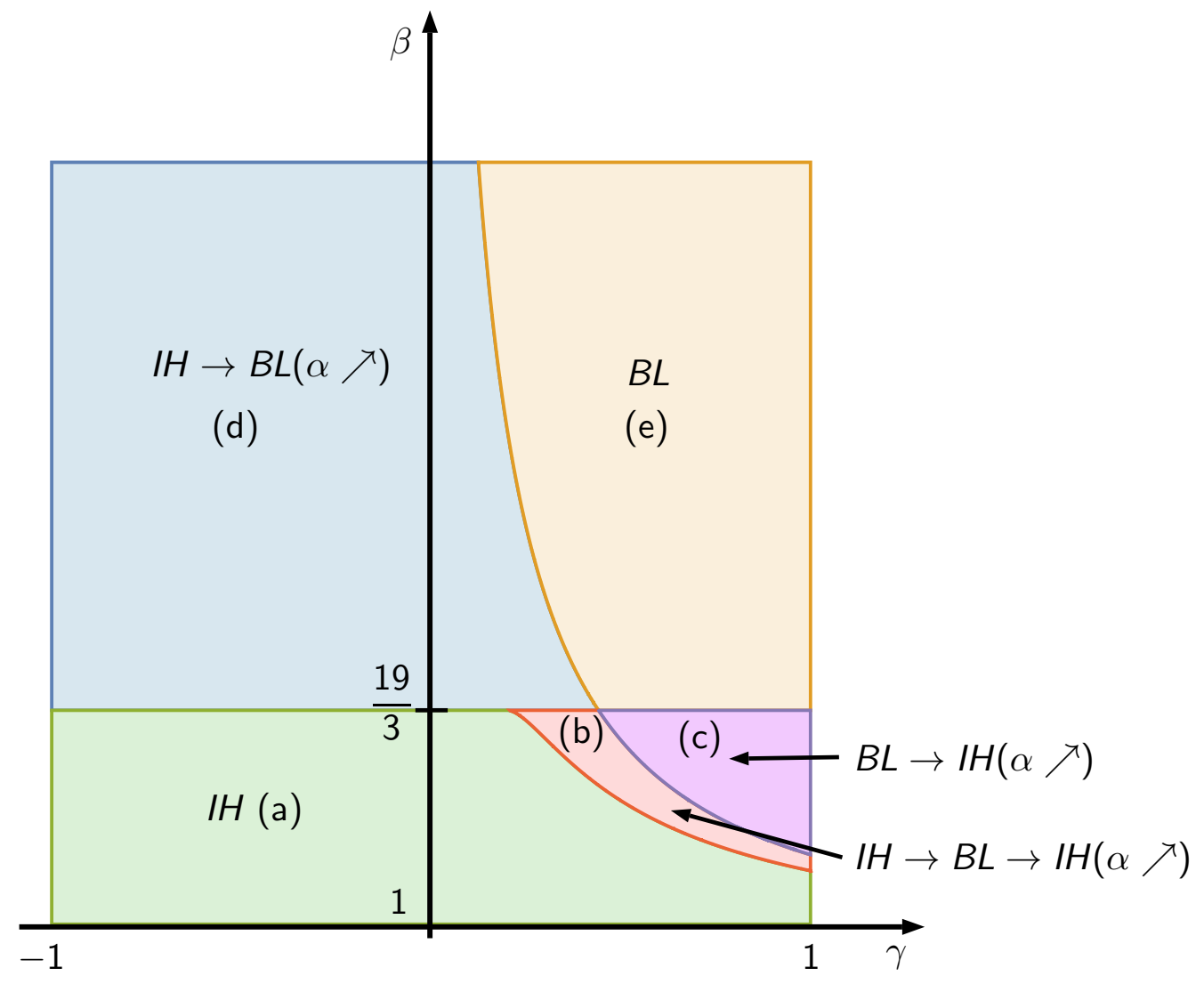

Figure 3: Optimal business model in the $(\gamma, \beta)$ space.

\section{Discussion and conclusions}

Despite the pervasiveness of brand licensing across industries, there is a need to understand the conditions under which brand owners should opt for this business model to extend their brands and, relatedly, what characterizes an optimal licensing contract. In this paper, we offer a comprehensive dynamic model that analyzes both needs. In doing so, we have built on insights from research on brand extension and brand licensing, as well as on technological licensing. Our model was particularly informed by studies on the degree of dissimilarity between the brand and the extension product; the occurrence of reciprocal effects; the possibility that both parties can behave opportunistically, and the assumption of the brand owner/licensor's relative cost inefficiency.

Our analysis provides two sets of results. The first set of results hinges on our choice of considering a two-part tariff, which provides a fine grained picture of the structure of the optimal licensing contract (Raugust, 2012). While the fixed fee extracts all the licensee profit (net of investments in the extension category), the royalty rate is the variable part of the tariff that shapes the licensee's incentives. Previous research on brand licensing had yet to delineate the effects of appropriating the surplus (for the licensor) from the structuring of incentives (for the licensee) (Jayachandran 
et al., 2013). Likewise, the related literature on franchising has only explored the relationship between fixed fee and royalty rate (Kaufmann and Dant, 2001). By contrast, our model considers these two components of the tariff in terms of the degree of dissimilarity between the brand and the extension product, as well as the magnitude of the reciprocal effects. Our results suggest that, for a given level of dissimilarity, the royalty rate is always larger in the presence of brand dilution than in the presence of brand enhancement. Consistently, brand owners should apply a higher fixed fee in the presence of brand enhancement than in the presence of brand dilution, for a given level of dissimilarity. A noticeable consequence of these results is that the incentives should be designed to protect the value of the extension product, as the sum of the investments in the value of the extension (by the licensor and the licensee) is constant. This result is novel because previous research has highlighted the role of concerns about protecting soloìely the brand when setting the contractual terms (Jayachandran et al., 2013).

In our case, we also remarkably found that under brand dilution, the licensor increases the royalty rate - and thus reduces the effort of the licensee while increasing its own - in order to sustain brand value.

In line with extant research, our study confirms that opportunism influences royalty rates because venture partners cannot observe each other's effort levels (Jayachandran et al., 2013, Robinson et al., 2015). More interestingly, we suggest that royalty rates are set not only with the desire to partially correct the effects of the information asymmetry, but also to control for the reciprocal effects, which in our model are influenced by the degree of dissimilarity. Along this line, our analysis corroborates brand extension studies (Czellar, 2003) that uncovered the moderating role of (dis)similarity on reciprocal effects in the context of brand licensing.

The second set of results pertains to the choice of make-or-license, which is based on the working assumption that the licensee is always more cost-efficient in developing the extension product than the brand owner/licensor. Figure 3 depicts five possible occurrences that depend on the levels of the reciprocal effect and the brand owner's (relative) degree of cost inefficiency. Region (a) represents the case in which the licensor is only slightly less efficient than the licensee. Here, the former opts for in-house development regardless of the level of dissimilarity. Indeed, the brand owner has no reason to enter into an inefficient relationship (i.e., characterized by opportunistic behavior), especially when the extension product would harm brand value. Companies are especially likely to manage products in-house when they characterize a brand portfolio, so as to avoid the opportunism that accompanies an agency relationship. Instances of this include the eyewear division of Kering Group (see footnote 4), the accessories (bags, small leather goods) of Valentino, or the jewelry and watches division of Gucci. Usually, these in-house extensions are pursued via acquisition when dissimilarity is high, or via internal development when dissimilarity is low.

The region (d) identifies the situation in which the licensor is very inefficient, so the business model changes from in-house to licensing as dissimilarity increases. When dissimilarity is high, we identify this region as brand stretching, or merchandising: The brand owner exploits its brand strength to offer collateral products, such as consumer-oriented items and gadgets (e.g., Ferrari 
caps, Disney bathrobes). In this case, licensing is the preferred means for the brand owner/licensor to exploit the licensee's efficiency, and given that the spillover effect is negative, the damage to the brand is low.

The region (e) mirrors (a) and represents the situation where a very inefficient brand owner always opts for brand licensing, for any level of dissimilarity, in order to exploit the licensee's capabilities and take advantage of brand enhancement. This result is anecdotally supported by the brand extensions that, even if far from the core product, characterize the brand as a "lifestyle brand" (i.e., create an area of taste and style consistent with the brand). An instance of this is the brand Armani: Beyond its haute couture line Armani Privé and the fast fashion brand Armani

Exchange, the firm offers everything that one needs for a luxury lifestyle - from sweets and flowers to restaurants and hotels.

Finally, there are two areas that provide insightful, albeit less intuitive outcomes than those above. Region (c) posits the following question for the brand owner: "Why engage in a licensing agreement when the extension product is going to enhance my brand value, and I am not that inefficient?" The answer is that when the dissimilarity is low, the brand owner can still exploit the licensee's higher capacity and obtain a positive return on the brand value. As dissimilarity increases, the positive feedback diminishes; thus, the brand owner would be better off leveraging its own relative "efficiency" and avoiding a contract that could be undermined by opportunism.

Although a potential artefact of our study, region (b) delivers some interesting findings. Here the (relatively efficient) brand owner opts for in-house development at both the low and high dissimilarity levels, while pursuing licensing when dissimilarity is "intermediate". For low dissimilarity values, the brand owner benefits from brand enhancement without any contract inefficiency; for high dissimilarity values, the brand owner does not pursue the contract because the level of brand enhancement is hindered by the high dissimilarity. For intermediate values of dissimilarity, the brand owner accepts the inefficiency of the contract in order to exploit the licensee's greater productive efficiency and thereby obtain brand enhancement. While we cannot immediately substantiate this outcome with anecdotal evidence, we believe this region represents an interesting non-linear effect of dissimilarity on the make-or-license choice. Future research might give it more empirical attention.

\subsection{Implications}

The managerial and economic literatures have devoted scant attention to the context of brand licensing. Our analysis attempts to fill this gap by providing a comprehensive model that offers the simultaneous analysis of the optimal contract and the decision of whether to engage in such an agreement.

As for the literature on brand extensions, our study contributes to research on "the other side" of brand leveraging (Lane and Jacobson, 1997, p. 261), that is, the reciprocal effect exerted by the extension product on the brand value. Since the 1980s, extant research has largely explored the choice of whether or not to extend a brand, as well as the drivers of brand extension evaluations; 
however, there has been less attention on the strategic role of reciprocal effects, and specifically the implications of such feedback effects (e.g., Hariharan et al., 2014, Lane and Jacobson, 1997). By moving away from technological licensing and franchising, our model better addresses the nuances of brand licensing - by positing the existence of a feedback effect from the new product to the parent brand. Colucci et al. (2008) advanced that the risk of negative effect seems to outweigh the advantages of licensing, thereby affecting managers' choices; however, they only considered the adverse effect, which they proxied in their model with the degree of similarity. Our analysis goes a step further by explicitly encompassing both the positive and negative feedback effects, highlighting that reciprocal effects shape both the optimal licensing contract and the choice of make-or-license. Our study also supports the role of dissimilarity as a moderator of the reciprocal effects (as suggested in the context of brand extension). Robinson et al. (2015) showed that a higher "fit" (i.e., similarity) between the brand and the licensed product leads investors to better evaluate the brand, which would then increase the brand owner's royalty rates. Our study extends the knowledge about "fit" between parent brand and extension product, demonstrating that (dis)similarity affects both the level of royalty rates and fixed fee - and ultimately, the choice of make-or-license. Beyond possibly increasing the brand owner's cash flow, the relevance of the brand extension also drives the choice to license the brand and shapes the payment structure with the partner.

Finally, by adopting a framework in which the opportunism is two-sided, we provide a more suitable picture of the information asymmetries in a specific B2B relationship. By contrast, previous research has only considered the case of licensee opportunism (Colucci et al., 2008, Robinson et al., 2015). To this end, we drew on insights from the technological licensing and franchising literatures (Lafontaine et al., 1992) to better translate the two-sided opportunism case to brand licensing. We confirm that an incentivizing licensing contract can (partially) align both parties' goals. Yet, our analysis specifically uncovered that the contractual structure can be used to (partially) countervail the negative effect on the parent brand (in the case of brand dilution) and to better exploit the positive effect (in the case of brand enhancement).

To conclude, our study highlights a rich set of testable implications that could be an object of further empirical research. 


\section{Appendices}

\section{A First-best licensing contract}

If a complete contract can exist, it specifies the effort levels that maximize the joint profit of the firms, with the royalty rate set to zero, in order not to distort the output choice on the extension market. The complete contract also specifies a fixed fee that transfers to the brand owner all the surplus from the licensing relationship.

For $s^{F B}=0$, the quantity that maximizes the profit from the sales of the extension product is $q^{F B}=\frac{e_{b}+e_{\ell}}{2}$. At this quantity, the net joint profit of the firms is

$$
\pi^{F B}\left(e_{b}, e_{\ell}\right)=\frac{1}{4}\left[2 e_{b}\left(2+e_{\ell}\right)+\frac{4 \gamma}{1+\alpha} e_{\ell}-3 e_{b}^{2}-3 e_{\ell}^{2}\right]
$$

which is also the profit accruing to the brand owner. By maximizing $\pi^{F B}$ with respect to the effort levels we get:

$$
e_{b}^{F B}=\frac{3+3 \alpha+\gamma}{4+4 \alpha}, \quad e_{\ell}^{F B}=\frac{1+\alpha+3 \gamma}{4+4 \alpha} .
$$

It is easy to ascertain that, while $e_{b}^{F B}$ is always positive, $e_{\ell}^{F B}$ is so only for $\gamma>-\frac{1+\alpha}{3}$. As a consequence, the effort levels in (33) are meaningful in this parameter constellation only. It is immediate to observe that, in this region, $e_{b}^{F B}>e_{b}^{*}$ : the effort of the brand owner is always larger under complete contracts. Yet, this is not the case for the licensee, indeed $e_{\ell}^{F B} \gtreqless e_{\ell}^{*} \Leftrightarrow \gamma \gtreqless-\frac{1+\alpha}{6}$. We can derive the brand owner profit, which are

$$
\pi^{F B}\left(e_{b}^{F B}, e_{\ell}^{F B}\right)=\frac{1}{8}\left[\frac{\gamma(2 \alpha+3 \gamma+2)}{(\alpha+1)^{2}}+3\right]
$$

A simple comparison shows that $\pi^{F B}\left(e_{b}^{F B}, e_{\ell}^{F B}\right)>\pi_{b}^{*}$.

When $\gamma \leq-\frac{1+\alpha}{3}$, the first-best contractual effort of the licensee is non-positive. Accordingly, the values in (33) are no longer meaningful because the brand owner only exerts effort. To find the value of $e_{b}$ in this case we consider $\pi^{F B}(\cdot)$ evaluated at $e_{\ell}=0$ :

$$
\pi^{F B}\left(e_{b}, 0\right)=\frac{1}{4}\left(4 e_{b}-3 e_{b}^{2}\right)
$$

which is maximized for $e_{b}=\frac{2}{3}$. At this effort level $\pi^{F B}\left(\frac{2}{3}, 0\right)=\frac{1}{3}$. It is a simple matter of algebra to prove that, in this case as well, the profit under the first best contract exceeds that of the second best one. 


\section{B Proof of Proposition 2 and 3}

The profit of the brand owner at the equilibrium of the licensing subgame is:

$$
\pi_{b}^{*}=\frac{30(1+\alpha) \gamma+73(1+\alpha)^{2}+9 \gamma^{2}}{216(1+\alpha)^{2}}
$$

and that at the equilibrium of the in-house development:

$$
\hat{\pi}_{i}=\frac{1}{12}\left[\frac{(4+\alpha)^{2}}{(\alpha+1)^{2}(3 \beta-1)}+4\right] .
$$

Taking the difference between the two functions and rearranging terms we obtain

$$
\begin{aligned}
& \Delta \pi(\alpha ; \beta, \gamma) \equiv \pi_{b}^{*}-\hat{\pi}_{i}= \\
& \quad \frac{\alpha^{2}(3 \beta-19)+\alpha[30(3 \beta-1) \gamma+6 \beta-146]+9(3 \beta-1) \gamma^{2}+30(3 \beta-1) \gamma+3 \beta-289}{216(\alpha+1)^{2}(3 \beta-1)} .
\end{aligned}
$$

It is clear by inspection that the denominator of $\Delta \pi(\cdot)$ is positive and continuous under Assumption A.1, thus the relative profitability of brand licensing versus in-house development depends upon the sign of the numerator only. Let $N(\alpha ; \beta, \gamma)$ denote the numerator of (38), which we are going to analyze as a (quadratic) function of $\alpha$. In particular, by combining the information about the concavity and number of roots of the numerator, we will be able to derive the conditions under which brand licensing is preferred to in-house development or the opposite, and whether the dissimilarity parameter $\alpha$ plays a role in this choice. It will be useful to define the following:

$$
\begin{gathered}
N_{0} \equiv N(0 ; \beta, \gamma)=\left(9 \gamma^{2}+30 \gamma\right)(3 \beta-1)+3 \beta-289 \\
\alpha_{c} \equiv\left\{\alpha:\left.\frac{\partial N(\cdot)}{\partial \alpha}\right|_{\alpha=\alpha_{c}}=0\right\}=-\frac{3 \beta(15 \gamma-1)+15 \gamma+73}{19-3 \beta},
\end{gathered}
$$

and

$$
N_{c} \equiv N\left(\alpha_{c} ; \beta, \gamma\right)=\frac{54(3 \beta-1)\{\gamma[(12 \beta-1) \gamma-30]+3\}}{19-3 \beta} .
$$

$N_{0}$ is the value of $N(\cdot)$ for $\alpha=0, \alpha_{c}$ is the value of $\alpha$ for which the first-order partial derivative of $N(\cdot)$ is zero and $N_{c}$ is the value of the function $N(\cdot)$, computed at $\alpha_{c}$.

Before proceeding further, it is instructive to identify the following loci:

$$
\begin{aligned}
& N_{0}=0 \quad \Leftrightarrow \quad \beta=\frac{96}{9 \gamma^{2}+30 \gamma+1}+\frac{1}{3}, \\
& \alpha_{c}=0 \quad \Leftrightarrow \quad \beta=\frac{24}{15 \gamma+1}+\frac{1}{3}, \\
& N_{c}=0 \quad \Leftrightarrow \quad \beta=\frac{\gamma(\gamma+30)-3}{12 \gamma^{2}},
\end{aligned}
$$

which are depicted in Figure 4. 


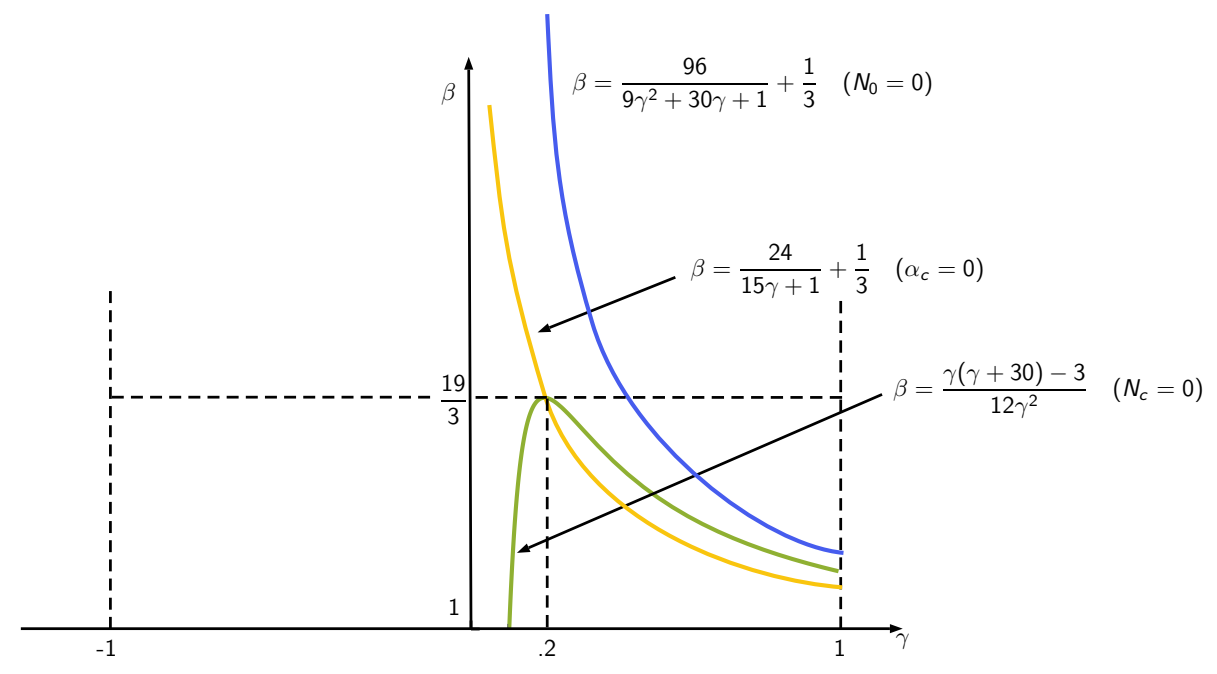

Figure 4: The loci $N_{0}=0, \alpha_{c}=0, N_{c}=0$.

This said, as a first observation notice that the second-order partial derivative of $N(\cdot), \frac{\partial^{2} N(\cdot)}{\partial \alpha^{2}}=$ $6 \beta-38 \gtreqless 0 \Leftrightarrow \beta \gtreqless \frac{19}{3}$, which implies that $N(\cdot)$ is a concave parabola for $\beta>\frac{19}{3}$ and a convex one for $\beta<\frac{19}{3} .{ }^{17}$ We will treat the cases separately. It will prove useful to keep in mind that the sign of the denominators of (40) and (41) changes in the regions $1<\beta<\frac{19}{3}$ and $\frac{19}{3}<\beta$.

\section{B.1 Proof of Proposition $2\left(1<\beta<\frac{19}{3}\right)$}

$N(\cdot)$ is a concave parabola, therefore we know that:

(i) $\alpha_{c}$ is the value of $\alpha$ for which $N(\cdot)$ is at its maximum,

(ii) $N_{c}$ is the value of $N(\cdot)$ at the maximum,

(iii) $\lim _{\alpha \rightarrow \infty} N(\cdot)=-\infty$.

Point (iii) allows us to conclude that for $\alpha$ "large enough" $N(\cdot)$ is negative and thus the optimal business model is In-House development (IH hereafter). Therefore, the issue is to know whether for "small enough" $\alpha$ Brand Licensing (BL hereafter) can be the optimal choice instead. We start by analyzing the case where there is no other optimal choice than IH and move to the case of possible different optimal choices afterwards.

\section{B.1.1 IH optimal choice for all $\alpha$}

Two possible configurations result in IH as the dominant choice for the brand owner, for any value of $\alpha$ : (1) $N_{c} \leq 0$ and (2) $N_{c}>0 \cap \alpha_{c}<0 \cap N_{0}<0$.

\footnotetext{
${ }^{17}$ The case $\beta=\frac{19}{8}$, where $N(\cdot)$ is a straight line is briefly discussed at the end of this proof.
} 
Case (1). The condition is:

$$
N_{c}<0 \Leftrightarrow \beta<\frac{\gamma(30+\gamma)-3}{12 \gamma^{2}}
$$

which can be fulfilled because, the locus $N_{c}=0$ has a maximum value of $\frac{19}{3}$ for $\gamma=.2$ (see fig. 4), which is the maximum value $\beta$ can take too.

Case (2). The set of conditions here is:

$$
\left\{\begin{aligned}
\alpha_{c}<0 & \Leftrightarrow \beta<\frac{24}{15 \gamma+1}+\frac{1}{3}, \\
N_{c}>0 & \Leftrightarrow \beta>\frac{\gamma(30+\gamma)-3}{12 \gamma^{2}}, \\
N_{0}<0 & \Leftrightarrow \beta<\frac{96}{9 \gamma^{2}+30 \gamma+1}+\frac{1}{3} .
\end{aligned}\right.
$$

By virtue of the discussion above, the first condition is more stringent than the third one, and it is easy to prove that $\frac{24}{15 \gamma+1}+\frac{1}{3}$ is actually larger than $\frac{19}{3}$ for all the values of $\gamma$ such that $\frac{\gamma(30+\gamma)-3}{12 \gamma^{2}}<\beta<\frac{24}{15 \gamma+1}+\frac{1}{3}$. Furthermore, $\frac{\gamma(30+\gamma)-3}{12 \gamma^{2}}=\frac{24}{15 \gamma+1}+\frac{1}{3}=\frac{19}{3}$ for $\gamma=.2$ (see Figure 4). We summarize the above discussion in the following:

Lemma 1. Under Assumption A.1 and $1<\beta<\frac{19}{3}$, IH is the only optimal business model when:

(i) $-1<\gamma<.2$ and $\beta>\frac{\gamma(30+\gamma)-3}{12 \gamma^{2}}$,

(ii) $.2<\gamma<1$ and $\beta<\frac{\gamma(30+\gamma)-3}{12 \gamma^{2}}$.

\section{B.1.2 BL optimal choice for "small" $\alpha$, IH optimal choice for "large" $\alpha$.}

For BL to be the optimal choice when $\alpha$ is small, $N(\cdot)$ has to be one and only one positive root. This happens when $N(\cdot)$ is positive for $\alpha=0$, requiring:

$$
N_{0}>0 \Leftrightarrow \beta>\frac{96}{9 \gamma^{2}+30 \gamma+1}+\frac{1}{3},
$$

and yields:

Lemma 2. Under Assumption A.1 and $1<\beta<\frac{19}{3}$, when $\beta>\frac{96}{9 \gamma^{2}+30 \gamma+1}+\frac{1}{3}$ a threshold value for $\alpha$ exists, $\tilde{\alpha}>0$ such that for $0<\alpha<\tilde{\alpha}$ the optimal business model is BL, for $\tilde{\alpha}<\alpha$ the optimal business model is IH.

\section{B.1.3 IH for "small" and "large" $\alpha$, BL for "intermediate" $\alpha$.}

A last possible occurrence has to be tackled, namely a possible non-linear behavior of the optimal business model relative to $\alpha$, which can emerge when $N(\cdot)$ has two positive and distinct roots. This 
requires that $\alpha_{c}>0 \cap N_{c}>0 \cap N_{0}<0$, that is to say:

$$
\left\{\begin{aligned}
\alpha_{c}>0 & \Leftrightarrow \beta>\frac{24}{15 \gamma+1}+\frac{1}{3}, \\
N_{c}>0 & \Leftrightarrow \beta>\frac{\gamma(30+\gamma)-3}{12 \gamma^{2}}, \\
N_{0}<0 & \Leftrightarrow \beta<\frac{96}{9 \gamma^{2}+30 \gamma+1}+\frac{1}{3} .
\end{aligned}\right.
$$

From the above analysis, we know that, as long as $1<\beta<\frac{19}{3}$ the second condition is more stringent than the first, which leads us to state

Lemma 3. Under Assumption A.1 and $1<\beta<\frac{19}{3}$, when $\frac{\gamma(30+\gamma)-3}{12 \gamma^{2}}<\beta<\frac{96}{9 \gamma^{2}+30 \gamma+1}+\frac{1}{3}$ two threshold values for $\alpha$ exist, $\check{\alpha}$ and $\hat{\alpha}$, with $0<\check{\alpha}<\hat{\alpha}$ such that for $0<\alpha<\check{\alpha}$ the optimal business model is IH, for $\check{\alpha}<\alpha<\hat{\alpha}$ the optimal business model is BL and for $\hat{\alpha}<\alpha$ the optimal business model is IH.

Proposition 2 directly follows from Lemmata 1 to 3.

\section{B.2 Proof of Proposition $3\left(\beta>\frac{19}{3}\right)$}

$N(\cdot)$ is a convex parabola, therefore we know that:

(i) $\alpha_{c}$ is the value of $\alpha$ for which $N(\cdot)$ is at its minimum,

(ii) $N_{c}$ is the value of $N(\cdot)$ at the minimum,

(iii) $\lim _{\alpha \rightarrow \infty} N(\cdot)=\infty$.

Point (iii) allows us to conclude that for $\alpha$ "large enough" $N(\cdot)$ is positive and thus the optimal business model is BL. Mirroring the proof of Proposition 2, the question is to know whether for "small enough" $\alpha$ IH can be the optimal choice instead. We start by analyzing the case where there is no other optimal choice than BL and move to the case of possible different optimal choices afterwards.

\section{B.2.1 BL optimal choice for all $\alpha$}

There is no other optimal choice than BL for $\beta>\frac{19}{3}$ in two possible cases: (1) $N_{c} \geq 0$ (2) $N_{c}<0 \cap \alpha_{c}<0 \cap N_{0}>0 .{ }^{18}$

Case (1). The condition is:

$$
N_{c} \geq 0 \Leftrightarrow \beta \leq \frac{\gamma(30+\gamma)-3}{12 \gamma^{2}}
$$

Under Assumption $A .1$ and $\beta>\frac{19}{3}$ this can never be true because the maximum value that the term on the right-hand side of the second inequality can assume is $\frac{19}{3}$ (for $\gamma=.2$ ). Since by assumption $\beta$ is larger than that value, we conclude with the following:

Remark 1. Under $A .1$ and $\beta>\frac{19}{3}, N_{c}<0$.

\footnotetext{
${ }^{18}$ In the following, the expression -say- $N_{c}>0$ stands for " $\{\beta, \gamma\}: N_{c}>0$ is true".
} 
Case (2). Remark 1 allows to simplify the conditions stated above, which reduce to:

$$
\begin{cases}\alpha_{c}<0 & \Leftrightarrow \beta>\frac{24}{15 \gamma+1}+\frac{1}{3}, \\ N_{0}>0 & \Leftrightarrow \beta>\frac{96}{9 \gamma^{2}+30 \gamma+1}+\frac{1}{3} .\end{cases}
$$

It is a matter of simple calculations to show that, for $\beta>\frac{19}{3}$ the second conditions is more stringent than the first, which allows us to state the following:

Lemma 4. Under Assumption A.1 and $\beta>\frac{19}{3}$, when $\beta>\frac{96}{9 \gamma^{2}+30 \gamma+1}+\frac{1}{3} B L$ is the only optimal choice for the brand owner.

\section{B.2.2 IH optimal for "small" $\alpha$, BL optimal for "large" $\alpha$}

Let us consider now the situation where IH is the optimal choice for suitable "small" values of $\alpha$. This means that, in that parameter range, $N(\cdot)$ is negative and then, as remarked above becomes positive, which amounts to saying that $N(\cdot)$ has one and only one positive root. The conditions insuring this are $N_{c}<0$ and $N_{0}>0$. However, Remark 1 insures that the first condition is satisfied for $\beta>\frac{19}{3}$ therefore the unique condition to be checked in this case is:

$$
N_{0}<0 \Leftrightarrow \beta>\frac{96}{9 \gamma^{2}+30 \gamma+1}+\frac{1}{3} \text {. }
$$

We conclude that, in this case a critical value of $\alpha$ exists, $\bar{\alpha}$ such that $N(\cdot)$ is negative for $\alpha$ lesser than that threshold and positive for $\alpha$ larger than the threshold. We summarize the economic intuition in:

Lemma 5. Under Assumption $A .1$ and $\beta>\frac{19}{3}$, when $\beta>\frac{96}{9 \gamma^{2}+30 \gamma+1}+\frac{1}{3}$ a threshold value for $\alpha$ exists, $\bar{\alpha}$ such that for $0<\alpha<\bar{\alpha}$ the optimal business model is IH, for $\bar{\alpha}<\alpha$ the optimal business model is $B L$.

A third case has to be considered, namely that where the optimal business model is non-linear in $\alpha$ because $N(\cdot)$ has two positive roots, implying that, starting from a low value of $\alpha$ the optimal choice is $\mathrm{BL}$, then it becomes $\mathrm{IH}$ and finally is gets back to BL. This requires that:

$$
\left\{\begin{array}{l}
\alpha_{c}>0 \quad \Leftrightarrow \beta>\frac{24}{15 \gamma+1}+\frac{1}{3}, \\
N_{c}<0, \\
N_{0}>0 \quad \Leftrightarrow \beta>\frac{96}{9 \gamma^{2}+30 \gamma+1}+\frac{1}{3} .
\end{array}\right.
$$

However, it is clear by the discussion of (50) that the first and third conditions of (52) are not consistent with each other, thereby allowing us to discard the possibility of a non-linear behavior of the choice of the optimal business model relative to $\alpha$ when $\beta>\frac{19}{3}$. Proposition 3 Directly follows from Lemmata 4 and 5 . 
For the sake of completeness we briefly hint at the cutting-edge case $\beta=\frac{19}{3}$. In this case $N(\cdot)$ is linear and in $\alpha$ :

$$
N\left(\alpha ; \frac{19}{3}, \gamma\right)=54 \alpha(10 \gamma-2)+54\left(3 \gamma^{2}+10 \gamma-5\right)
$$

Furthermore, this function is increasing in $\alpha$ for $\gamma<\frac{1}{5}$ and decreasing otherwise and has a zero for $\alpha=\frac{3 \gamma^{2}+10 \gamma-5}{2(1-5 \gamma)}$. In intuitive terms, $\mathrm{BL}$ is the optimal business model only in the case of a "non-small" positive reciprocal effect, whereas IH is preferred when the reciprocal effect is positive, but small, and negative. 


\section{References}

Aaker, D. A. and Keller, K. L. (1990). Consumer evaluations of brand extensions. The Journal of Marketing, 54:27-41.

Ahluwalia, R. and Gürhan-Canli, Z. (2000). The effects of extensions on the family brand name: An accessibility-diagnosticity perspective. Journal of Consumer Research, 27(3):371-381.

Bhattacharyya, S. and Lafontaine, F. (1995). Double-sided moral hazard and the nature of share contracts. The RAND Journal of Economics, page 761-781.

Bottomley, P. A. and Holden, S. J. (2001). Do we really know how consumers evaluate brand extensions? empirical generalizations based on secondary analysis of eight studies. Journal of Marketing Research, 38(4):494-500.

Boush, D. M. and Loken, B. (1991). A process-tracing study of brand extension evaluation. Journal of Marketing Research, 28(1):16-28.

Broniarczyk, S. M. and Alba, J. W. (1994). The importance of the brand in brand extension. Journal of Marketing Research, page 214-228.

Buratto, A. and Zaccour, G. (2009). Coordination of advertising strategies in a fashion licensing contract. Journal of optimization theory and applications, 142(1):31-53.

Cabral, L. M. (2000). Stretching firm and brand reputation. RAND Journal of Economics, $31: 658-673$.

Cabral, L. M. (2009). Umbrella branding with imperfect observability and moral hazard. International Journal of Industrial Organization, 27(2):206-213.

Cachon, G. P. and Lariviere, M. A. (2005). Supply chain coordination with revenue-sharing contracts: strengths and limitations. Management science, 51(1):30-44.

Choi, J. P. (2001). Technology transfer with moral hazard. International Journal of Industrial Organization, 19(1):249-266.

Colucci, M., Montaguti, E., and Lago, U. (2008). Managing brand extension via licensing: An investigation into the high-end fashion industry. International Journal of Research in Marketing, $25(2): 129-137$.

Corbellini, E. and Saviolo, S. (2014). Managing fashion and luxury companies. Etas Libri, Milan.

Czellar, S. (2003). Consumer attitude toward brand extensions: an integrative model and research propositions. International Journal of Research in Marketing, 20(1):97-115. 
de Groote, J. K., Mendini, M., and Gibbert, M. (2019). In the eye of the beholder: The role of cognitive style and similarity in the evaluation of brand extensions. Journal of Consumer Behaviour, 18(1):63-73.

Fernie, J. and Perry, P. (2019). Luxury fashion supply chain management. In Fernie, J. and Sparks, L., editors, Logistics and Retail Management, page 149-182. Kogan Page, London, fifth edition.

Fournier, S. and Boer, J. (2002). Calvin Klein, Inc. vs. Warnaco Group, Inc. Harvard Business School, Case 9-503-011.

Global, L. (2016). The top 150 global licensors. https://www.licenseglobal.com/ magazine-article/top-150-global-licensors-2. Accessed on June 2019.

Gürhan-Canli, Z. and Maheswaran, D. (1998). The effects of extensions on brand name dilution and enhancement. Journal of marketing research, 35(4):464-473.

Hakenes, H. and Peitz, M. (2008). Umbrella branding and the provision of quality. International Journal of Industrial Organization, 26(2):546-556.

Hariharan, V. G., Bezawada, R., and Talukdar, D. (2014). Aggregate impact of different brand development strategies. Management Science, 61(5):1164-1182.

Hernández-Murillo, R. and Llobet, G. (2006). Patent licensing revisited: Heterogeneous firms and product differentiation. International Journal of Industrial Organization, 24(1):149-175.

Jayachandran, S., Kaufman, P., Kumar, V., and Hewett, K. (2013). Brand Licensing: What Drives Royalty Rates? Journal of Marketing, 77(5):108-122.

John, D. R., Loken, B., and Joiner, C. (1998). The negative impact of extensions: can flagship products be diluted? The Journal of Marketing, page 19-32.

Kaufmann, P. J. and Dant, R. P. (2001). The pricing of franchise rights. Journal of Retailing, $77(4): 537-545$.

Keller, K. L. and Aaker, D. A. (1992). The effects of sequential introduction of brand extensions. Journal of Marketing Research, 29(1):35-50.

Keller, K. L., Apéria, T., and Georgson, M. (2008). Strategic brand management: A European perspective. Pearson Education.

Keller, K. L. and Sood, S. (2003). Brand equity dilution. MIT Sloan Management Review, 45(1):12.

Lafontaine, F. et al. (1992). Agency theory and franchising: some empirical results. RAND journal of Economics, 23(2):263-283.

Lane, V. and Jacobson, R. (1997). The reciprocal impact of brand leveraging: Feedback effects from brand extension evaluation to brand evalution. Marketing Letters, 8(3):261-271. 
LIMA (2018). Global Licensing Survey. https://licensinginternational.org/get-survey/. Accessed on June 2019.

Loken, B. and John, D. R. (1993). Diluting brand beliefs: when do brand extensions have a negative impact? The Journal of Marketing, page 71-84.

Loken, B., Joiner, C., and Houston, M. (2010). Leveraging a brand through brand extension: A review of two decades of research. Brands and brand management: Contemporary research perspectives, page 11-41.

Loveday, S. (2018). Global sales of licensed goods hit $\$ 271.6 \mathrm{bn}$ in 2017 . https:// www. licensingsource.net/global-sales-of-licensed-goods-hit-271-6bn-in-2017/. Accessed on June 2019.

Michel, G. and Donthu, N. (2014). Why negative brand extension evaluations do not always negatively affect the brand: The role of central and peripheral brand associations. Journal of Business Research, 67(12):2611-2619.

Miklós-Thal, J. (2012). Linking reputations through umbrella branding. Quantitative marketing and economics, 10(3):2335-374.

Miniard, P. W., Jayanti, R. K., Alvarez, C. M., and Dickson, P. R. (2018). What brand extensions need to fully benefit from their parental heritage. Journal of the Academy of Marketing Science, 46(5):948-963.

Monga, A. B. and John, D. R. (2010). What makes brands elastic? the influence of brand concept and styles of thinking on brand extension evaluation. Journal of Marketing, 74(3):80-92.

Moorthy, S. (2012). Can brand extension signal product quality? Marketing science, 31(5):756-770.

Morrin, M. (1999). The impact of brand extensions on parent brand memory structures and retrieval processes. Journal of Marketing Research, 36(4):517-525.

Park, C. W., Milberg, S., and Lawson, R. (1991). Evaluation of brand extensions: the role of product feature similarity and brand concept consistency. Journal of consumer research, 18(2):185-193.

Pina, J. M., Riley, F. D., and Lomax, W. (2013). Generalizing spillover effects of goods and service brand extensions: A meta-analysis approach. Journal of Business Research, 66(9):1411-1419.

Pnevmatikos, N., Vardar, B., and Zaccour, G. (2018). When should a retailer invest in brand advertising? European Journal of Operational Research, 267(2):754-764.

Rasmusen, E. B. (2016). Leveraging of reputation through umbrella branding: The implications for market structure. Journal of Economics \& Management Strategy, 25(2):261-273. 
Raugust, K. (2012). The licensing business handbook: how to make money, protect trademarks, extend product lines, enhance merchandising, control use of images, and more, by licensing characters, teams, celebrities, events, trademarks, fashion, likenesses, designs 8 logos! EPM communications, New York.

Robinson, A. B., Tuli, K. R., and Kohli, A. K. (2015). Does brand licensing increase a licensor's shareholder value? Management Science, 61(6):1436-1455.

Salinas, E. M. and Pérez, J. M. P. (2009). Modeling the brand extensions' influence on brand image. Journal of Business Research, 62(1):50-60.

Saviolo, S. and Giannelli, B. (2001). Il licensing nel sistema moda. Evoluzione, criticità, prospettive. Etas Libri, Milano.

Swaminathan, V., Fox, R. J., and Reddy, S. K. (2001). The impact of brand extension introduction on choice. Journal of Marketing, 65(4):1-15.

Tauber, E. M. (1988). Brand leverage-strategy for growth in a cost-control world. Journal of advertising Research, 28(4):26-30.

Tauman, Y. and Zhao, C. (2018). Patent licensing, entry and the incentive to innovate. International Journal of Industrial Organization, 56:229-276.

Völckner, F. and Sattler, H. (2006). Drivers of brand extension success. Journal of Marketing, $70(2): 18-34$.

Wernerfelt, B. (1988). Umbrella branding as a signal of new product quality: An example of signalling by posting a bond. The RAND Journal of Economics, page 458-466.

Yeung, C. W. and Wyer Jr, R. S. (2005). Does loving a brand mean loving its products? The role of brand-elicited affect in brand extension evaluations. Journal of Marketing Research, 42(4):495-506. 


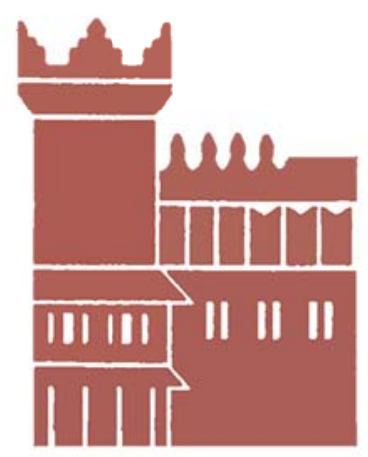

Alma Mater Studiorum - Università di Bologna DEPARTMENT OF ECONOMICS

Strada Maggiore 45

40125 Bologna - Italy

Tel. +39051 2092604

Fax +390512092664

http://www.dse.unibo.it 